This item was submitted to Loughborough's Research Repository by the author.

Items in Figshare are protected by copyright, with all rights reserved, unless otherwise indicated.

\title{
Thermo-mixed hydrodynamics of piston compression ring conjunction
}

PLEASE CITE THE PUBLISHED VERSION

http://dx.doi.org/10.1007/s11249-013-0163-5

VERSION

AM (Accepted Manuscript)

LICENCE

CC BY-NC-ND 4.0

\section{REPOSITORY RECORD}

Shahmohamadi, Hamed, Ramin Rahmani, Homer Rahnejat, Colin P. Garner, and P.D. King. 2019. "Thermomixed Hydrodynamics of Piston Compression Ring Conjunction”. figshare. https://hdl.handle.net/2134/12900. 
This item was submitted to Loughborough's Institutional Repository (https://dspace.lboro.ac.uk/) by the author and is made available under the following Creative Commons Licence conditions.

\section{creative
commons}

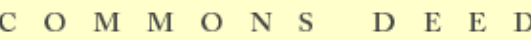

Attribution-NonCommercial-NoDerivs 2.5

You are free:

- to copy, distribute, display, and perform the work

Under the following conditions:

Attribution. You must attribute the work in the manner specified b the author or licensor.

Noncommercial. You may not use this work for commercial purposes.

No Derivative Works. You may not alter, transform, or build upon this work.

- For any reuse or distribution, you must make clear to others the license terms of this work.

- Any of these conditions can be waived if you get permission from the copyright holder.

Your fair use and other rights are in no way affected by the above.

This is a human-readable summary of the Leqal Code (the full license).

\section{Disclaimer 만}

For the full text of this licence, please go to: http://creativecommons.org/licenses/by-nc-nd/2.5/ 
(Accepted Version)

\title{
Thermo-mixed hydrodynamics of Piston Compression Ring Conjunction
}

\author{
H. Shahmohamadi, R. Rahmani ${ }^{*}$, H. Rahnejat, C.P. Garner and P.D. King \\ Wolfson School of Mechanical and Manufacturing Engineering, Loughborough University, \\ Loughborough, LE11 3TU, Leicestershire, UK \\ *Corresponding author, Email: r.rahmani@lboro.ac.uk
}

\begin{abstract}
A new method, comprising Navier-Stokes equations, Rayleigh-Plesset volume fraction equation, an analytical control-volume thermal mixed approach and asperity interactions is reported. The method is employed for prediction of lubricant flow and assessment of friction in the compression ring-cylinder liner conjunction. The results are compared with Reynoldsbased laminar flow with Elrod cavitation algorithm. Good conformance is observed for medium load intensity part of the engine cycle. At lighter loads and higher sliding velocity, the new method shows more complex fluid flow, possessing layered flow characteristics on account of pressure and temperature gradient into the depth of the lubricant film, which leads to a cavitation region with vapour content at varied volume fractions. Predictions also conform well to experimental measurements reported by other authors.
\end{abstract}

Keywords: Piston Ring conjunction, mixed mode friction, Navier-Stokes equations, RaleighPlesset volume fraction

\section{Introduction}

The primary function of the piston compression ring is to seal the combustion chamber. This prevents the escape of high-pressure gases from the combustion chamber and conversely lubricant leakage into the chamber. However, effective sealing function of the compression ring can result in increased friction and thus parasitic losses [1].The piston assembly accounts for approximately 35-45\% of engine frictional losses [2, 3]. Therefore, in order to improve engine performance as well as reducing emission levels, it is important to have a deeper understanding of frictional behaviour of piston-cylinder system as a prerequisite. The current 
(Accepted Version)

work addresses these issues with regard to the piston compression ring.

There have been many numerical predictions of compression ring-cylinder liner conjunction, where the analyses have included a host of parameters which interact with each other, making the tribology of ring-liner conjunction particularly complex. These parameters include the effect of the ring's axial profile along its contacting face-width with the cylinder liner and its surface topography [4], and the effect of evolving wear process upon friction and sealing effectiveness of the ring in an out-of-round bore [5,6]. These and similar analyses [7-13] have included mixed regime of lubrication, where direct interaction of surfaces can occur at piston dead centre reversals with momentary cessation of lubricant entraining motion into the contact under assumed fully flooded or starved inlet conditions. Although ring fitment analysis is taken into account in the works reported in [5,6,11,12], including in some cases with bore out-of-roundness, the ring bore conformability should also take into account the modal behaviour of the ring as described, for example, by Baker et al [14]. They showed that ring elastodynamics in fact conforms it to the bore in the high pressure region with a low sliding velocity (i.e. at the reversals). This ensures good ring sealing at the expense of increased friction. However, in some parts of the engine cycle, ring elastodynamics as well as its axial profile can exacerbate the convergent-divergent conjunctional passage and clearance, which suggests lubricant film rupture and the emergence of a cavitation region. This can also affect the compression ring sealing function. The effect of cavitation is studied by Chong et al [15], who used Elrod's approximation [16] to the Jakobsson and Floberg [17] and Olsson [18] (JFO) cavitation boundary condition. Chong et al [15] showed that cavitation formed at the lubricant film contact exit in the compression stroke reduces the lubricant availability at the TDC (Top Dead Centre) reversal, thus causing a starved contact in parts of the power stroke in the vicinity of the TDC.

Therefore, the multivariate nature of the problem is quite apparent. The current analysis combines the use of an open (free) exit boundary condition instead of an imposed cavitation boundary condition. This is achieved by solving the Navier-Stokes equations for multi-phase flow dynamics instead of the usual Reynolds equation. Additionally, this approach readily enables simultaneous solution with the energy equation. Thus, the effect of surface temperatures, and that caused through viscous shear of the lubricant in the conjunction, upon lubricant film formation and viscosity variation into the depth of the film are included in the solution. Unlike Reynolds or Elrod flow equations, with the Navier-Stokes equations the 


\section{(Accepted Version)}

pressure gradient across the film is retained. This enables more accurate prediction of viscous friction due to Poiseuille flow as well as in Couette shear. This approach together with inclusion of lubricant rheological state and asperity interactions, to represent boundary friction, has not hitherto been reported in literature.

\section{Problem Description}

Figure 1 is a schematic representation of ring-liner conjunction along the ring axial facewidth. The ring profile $h_{s}(x)$ is assumed to be parabolic with a maximum crown height of $c$ and a face-width of $b$ :

$$
h_{s}(x)=\frac{c x^{2}}{(b / 2)^{2}}
$$

The current analysis assumes good conformance of the ring to the liner surface in the circumferential direction of the bore. This simplifies the problem to a one dimensional contact, which is valid for ring-bore contact of bore diameter-to-ring face-width ratio: $2 \pi r_{0} / b \geq 30$ as shown by Haddad and Tian [19], which is applicable to the engine studied here. The engine studied here is a high performance V12 4-stroke naturally aspirated engine with specifications as detailed in Table 1.

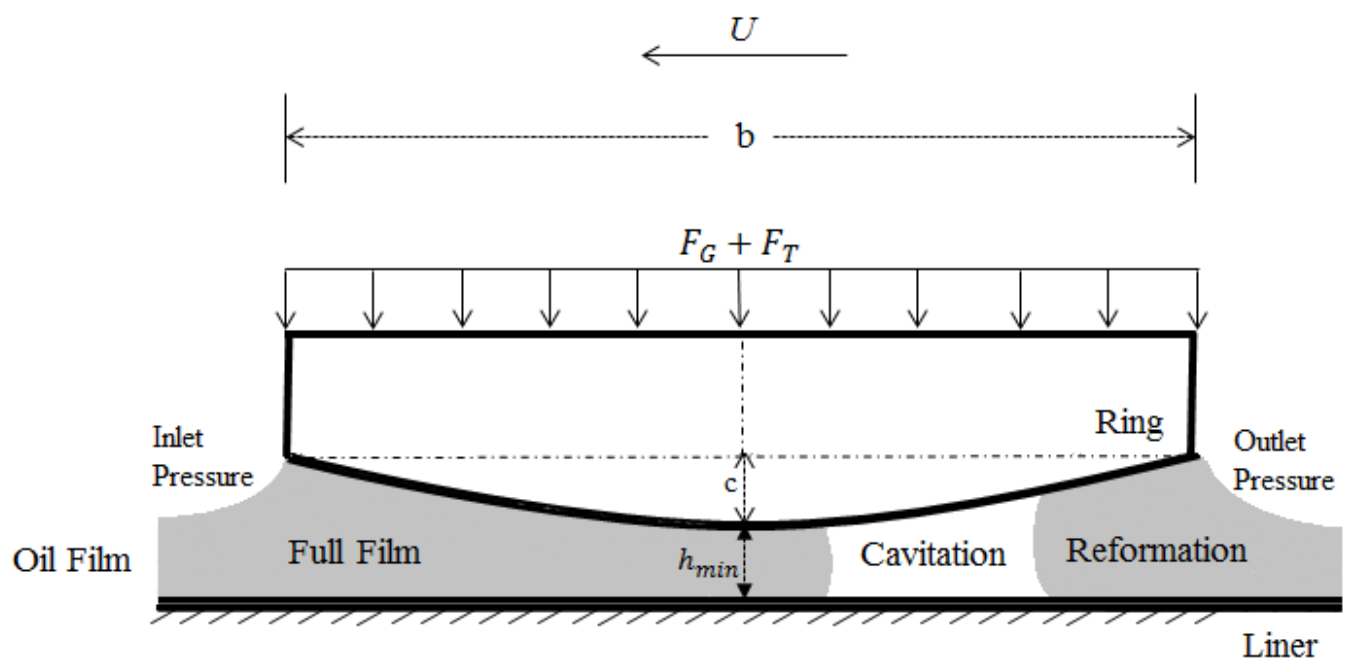

Figure1: 2D Diagram of piston ring-liner conjunction 
(Accepted Version)

Table1: Engine data

\begin{tabular}{|c|c|c|}
\hline Parameters & Values & Units \\
\hline Crank-pin radius, $r$ & 39.75 & $\mathrm{Mm}$ \\
\hline Connecting rod length, $l$ & 138.1 & $\mathrm{Mm}$ \\
\hline Bore nominal radius, $r_{0}$ & 44.52 & $\mathrm{Mm}$ \\
\hline Ring crown height, $c$ & 10 & $\mu \mathrm{m}$ \\
\hline Ring axial face-width, $b$ & 1.15 & $\mathrm{Mm}$ \\
\hline Ring radial width, $d$ & 3.5 & $\mathrm{Mm}$ \\
\hline Ring free end gap, $g$ & 10.5 & $\mathrm{Mm}$ \\
\hline
\end{tabular}

It is assumed that the ring does not undergo any relative motion with respect to the piston sliding at the velocity $U$. In practice, the ring may be subject to axial motion within its retaining groove; a motion termed as ring flutter. Thus, according to Rahnejat [20]:

$U(\varphi)=-r \omega \sin \varphi\left\{1+\cos \varphi\left[\left(\frac{l}{r}\right)^{2}-\sin ^{2} \varphi\right]^{-\frac{1}{2}}\right\}$

where $\varphi$ is the crank-angle, $l$ is the connecting rod length, $r$ the crank pin radius and $\omega$ is the engine rotational speed. Figure 2 shows the piston sliding speed variation for the engine speeds of 1500 and $6000 \mathrm{rpm}$ respectively. 


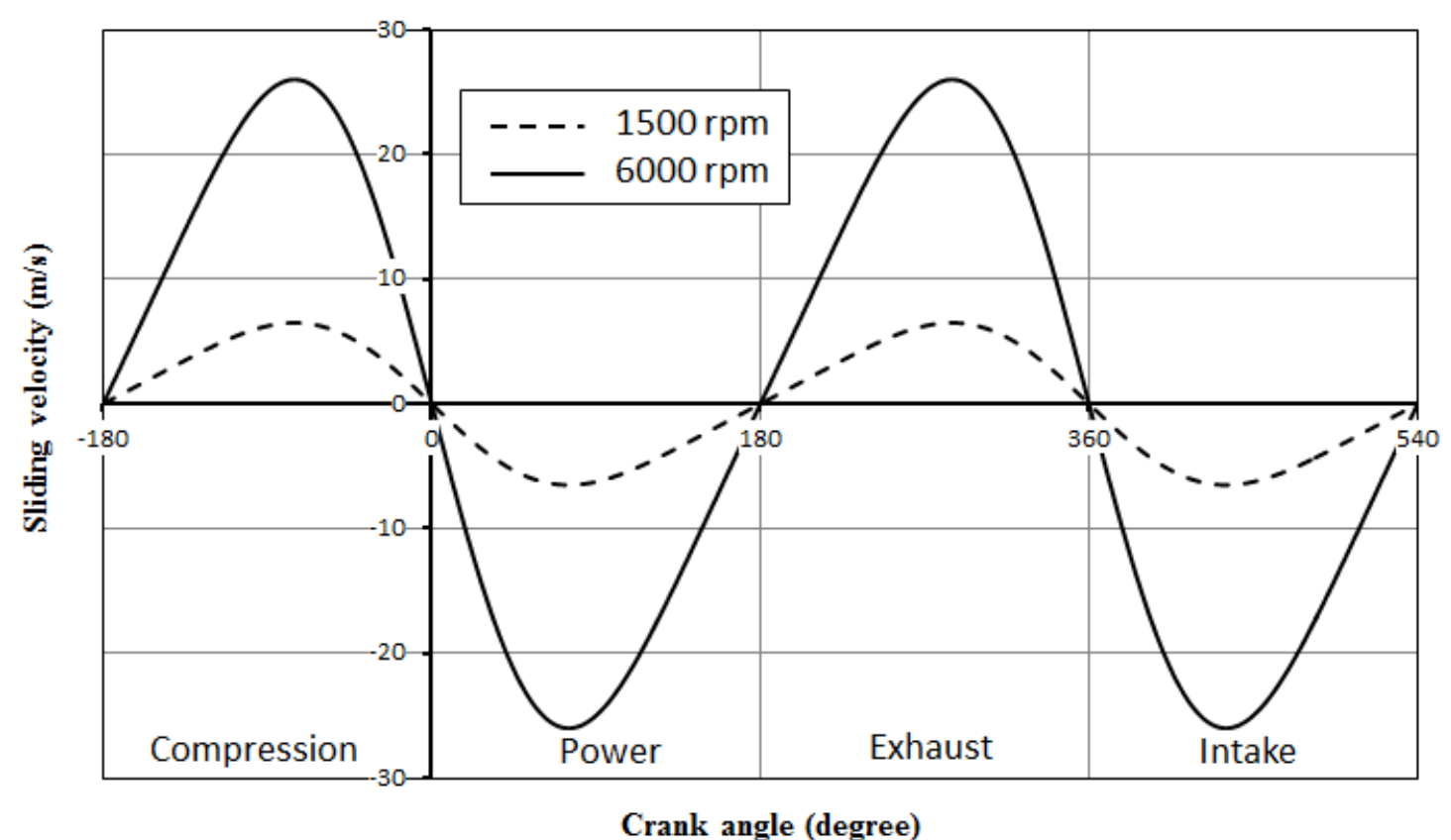

Figure 2: piston sliding speed for engine speeds of 1500 and $6000 \mathrm{rpm}$

Forces acting on the ring are considered as radial in-plane forces. In its radial plane, the ring is subjected to two outward forces: ring elastic tension force $F_{T}$ and the gas force $F_{G}$, acting on the inner rim of the ring. These forces strive to conform the ring to the bore surface. Thus, the total outward force (towards the liner interface), acting on the ring is: $F=F_{T}+F_{G}$. The ring tension force, $F_{T}$, is obtained as [21]:

$F_{T}=p_{e} b r_{0} \quad$ (where $p_{e}=\frac{g E I}{3 \pi b r_{0}^{4}}$ )

where, $p_{e}$ is the elastic pressure, $r_{0}$ is the bore nominal radius and $g$ is the ring end gap in its free (unfitted) state. The gas force acting on the back of the ring varies according to the chamber pressure in an engine cycle, thus:

$F_{G}(\varphi)=2 \pi b r_{0} p_{g}(\varphi)$

A gas blow-by analysis is required to obtain the exact value of gas pressure acting behind the ring. In the current analysis it is assumed that the gas pressure behind the ring is equal to the in-cylinder gas pressure. 
These outward forces (ring elastic tension and the gas force) are opposed by the contact force generated as the result of combined actions of generated conjunctional hydrodynamic pressures and the load share carried by the direct contact of surfaces themselves. The latter is often the load shared by a small portion of asperities on the opposing surfaces. Thus, the instantaneous contact load is determined as $W(\varphi)=W_{a}(\varphi)+W_{h}(\varphi)$, where the load carried by any film of lubricant is the integrated pressure distribution as:

$$
W_{h}(\phi)=2 \pi r_{0} \int_{0}^{b} p_{h}(\phi) d x d y
$$

As shown in Figure 1, in general, the contact region may be considered as comprising of three distinct regions: (i) full film (a coherent lubricant film region), (ii) film rupture and cavitation, and (iii) lubricant film reformation. The Elrod cavitation model is the usual basis for the tribological analysis, taking into account these various conjunctional regions. To describe the physics of fluid flow in the cavitated region, in which at least these various states of lubricant film co-exist, a suitable two-phase flow model needs to be employed alongside the use of the Navier-Stokes equations. This would be an elegant approach which for moderately and heavily loaded conditions represents a reasonable compromise between computational speed and predictive accuracy [22]. However, it can be fairly complex to implement.

\section{Numerical Model}

\subsection{General Navier-Stokes and energy equations}

The general continuity and Navier-Stokes momentum equations for compressible viscous fluid flow can be described as [23]:

$\frac{D \rho}{D t}+\rho \nabla \cdot \vec{V}=0$

$\rho \frac{D \vec{V}}{D t}=-\nabla p+\nabla \cdot\left(\bar{\tau}_{i j}\right)+\vec{F}$

where $\frac{D}{D t}$ is the covariant derivative operator, $\rho$ is the lubricant density, $p$ is the pressure, $\bar{\tau}_{i j}$ is the viscous stress tensor and $\vec{F}$ is the body force field vector. In addition, 
$\vec{V}=U \hat{i}+V \hat{j}+W \hat{k}$ is the velocity vector in which $U$ is the component of velocity in the direction of axial lubricant flow entrainment, $V$ is that in the side-leakage direction; along the $y$-axis (which may reasonably be discarded as there is negligible side-leakage in the thin film ring-bore conjunction), and $W$ is the squeeze film velocity, $\frac{\partial h}{\partial t}$. The viscous stress tensor is:

$\bar{\tau}_{i j}=\eta\left(\frac{\partial U_{i}}{\partial x_{j}}+\frac{\partial U_{j}}{\partial x_{i}}-\delta_{i j} \frac{2}{3} \nabla \cdot \vec{V}\right)$

where $\eta$ is the effective lubricant dynamic viscosity, $\delta_{i j}$ is the Kronecker delta and it is defined as:

$\delta_{i j}= \begin{cases}0 & \text { if } i \neq j \\ 1 & \text { if } i=j\end{cases}$

One possibility in a CFD model is to evaluate fluid viscosity as a function of pressure and temperature along the liner and into the depth of the lubricant film. The latter is neglected in the conventional hydrodynamic lubrication approaches, which are based on Reynolds equation. Finally, the energy equation can be stated as [23]:

$\rho \frac{D H}{D t}=\frac{D p}{D t}+\nabla \cdot(k \nabla \theta)+\bar{\tau}_{i j} \frac{\partial U_{i}}{\partial x_{j}}$

where $H$ is the fluid enthalpy, $\theta$ is the temperature and $k$ is the lubricant thermal conductivity.

\subsection{Cavitation model - vapour mass fraction and vapour transport equations}

With cavitation, the liquid-vapour mass transfer (evaporation and condensation) is governed by the vapour transport equation as [24]:

$\frac{\partial}{\partial t}\left(\alpha_{v} \rho_{v}\right)+\nabla \cdot\left(\alpha_{v} \rho_{v} \vec{V}_{v}\right)=R_{e}-R_{c}$

where $\rho_{v}$ is the vapour density, $\vec{V}_{v}$ is the velocity vector of the vapour phase, $R_{e}$ and $R_{c}$ are mass transfer source terms related to the growth and collapse of the vapour bubbles respectively. The growth and collapse of a bubble cluster are modelled based on the Rayleigh-Plesset equation, describing the growth of a single vapour bubble in a liquid, which 
provides the rate equation, controlling vapour generation and condensation. Singhal et al [25] assumed that a working fluid is a mixture of liquid and vapour and introduced a modified form of the above equation, based upon the vapour mass fraction, $f_{\text {mass }}$ as:

$$
\frac{\partial}{\partial t}\left(\rho_{m} f_{\text {mass }}\right)+\nabla \cdot\left(\rho_{m} \vec{V}_{v} f_{\text {mass }}\right)=\nabla \cdot\left(\Gamma \nabla f_{\text {mass }}\right)+R_{e}-R_{c}
$$

where $\rho_{m}$ is the mixture density and $\Gamma$ is the diffusion coefficient. The mass transfer rate expressions are derived from the Rayleigh-Plesset equations, based upon limiting bubble size considerations (interface surface area per unit volume of vapour). These rates are functions of the instantaneous, local pressure and are given by:

$$
\begin{array}{ll}
R_{e}=C_{e} \frac{V_{c h}}{\sigma_{s}} \rho_{l} \rho_{v} \sqrt{\frac{2\left(p_{\text {sat }}-p\right)}{3 \rho_{l}}}\left(1-f_{\text {mass }}\right), & \text { for } p<p_{\text {sat }} \\
R_{c}=C_{c} \frac{V_{c h}}{\sigma_{s}} \rho_{l} \rho_{v} \sqrt{\frac{2\left(p-p_{\text {sat }}\right)}{3 \rho_{l}}} f_{\text {mass }}, & \text { for } p>p_{\text {sat }}
\end{array}
$$

where the suffices $l$ and $v$ denote the liquid and vapour phases respectively, $V_{c h}$ is a characteristic velocity, $\sigma_{s}$ is the surface tension coefficient of the liquid, $p_{\text {sat }}$ is the liquid saturation vaporisation pressure at a given temperature and $C_{e}$ and $C_{c}$ are empirical constants and are considered to be 50 and 0.01 respectively according to Kubota et al [26].

\subsection{Conventional hydrodynamic cavitation model (Elrod's method)}

For the engine under investigation, the ring perimeter-to-width ratio is over 100. Therefore, as a first approximation, the piston ring/liner conjunction can be viewed as an infinitely long slider bearing [7] (envisaged as unwrapped). Although this assumes uniform radial loading and neglects piston secondary motion as well as ring dynamics, the final results can provide some valuable predictions. If the flow is considered as laminar, the behaviour of most lubricated conjunctions can be predicted using Reynolds equation:

$\frac{\partial}{\partial x}\left(\frac{\rho h^{3}}{6 \eta} \frac{\partial p}{\partial x}\right)=U \frac{\partial}{\partial x}(\rho h)+2 \frac{d}{d t}(\rho h)$

Elrod's modification [16] provides an acceptable solution if cavitation is present: In the full film region of the contact both Couette and Poiseuille terms are considered, while in the 
cavitation region only Couette flow is taken into account and lubricant squeeze film motion [27]. To account for this, a switching term, $g_{s}$ is defined as:

$g_{s}=\left\{\begin{array}{lll}1 & \text { if } \xi \geq 1 \quad \text { (full film region) } \\ 0 & \text { if } 0<\xi<1 & \text { (cavitation region) }\end{array}\right.$

in which $\xi$ is defined as the fractional film content. This allows defining the contact pressure distribution as a function of film ratio $\xi$ as:

$p=g_{s} \beta \ln \xi+p_{c}$

where $p_{c}$ is the lubricant's cavitation vaporisation pressure and $\beta$ is the lubricant's bulk modulus. Reynolds equation is now modified using equations (15) and (17) as:

$\frac{\partial}{\partial x}\left(\frac{\rho h^{3}}{6 \eta} g_{s} \beta \frac{\partial \xi}{\partial x}\right)=U \frac{\partial}{\partial x}(\xi \rho h)+2 \frac{d}{d t}(\xi \rho h)$

Lubricant viscosity and density vary with contact pressures and temperatures as described in Section 3.5 below.

\subsection{Boundary conditions}

In both the Navier-Stokes and Elrod's models the following boundary conditions are used along the axial $x$-direction of the contact (i.e. along the ring face-width)

$\left\{\begin{array}{l}p_{h}(-b / 2)=p_{L} \\ p_{h}(+b / 2)=p_{U} \\ p_{h}\left(x_{c}\right)=p_{c}\end{array}\right.$

However, the Elrod model satisfies another pressure gradient boundary condition $\left.\frac{d p(x)}{d x}\right|_{x=x_{c}}=0$ at the film rupture point ( $x_{c}$ is the location of rupture point), whereas no artificial exit boundary condition needs to be stated with the Navier-Stokes approach.

\subsection{Lubricant rheology}

The lubricant bulk rheological properties including density and viscosity are affected by pressure and temperature [5]. The density-pressure relationship is [28]: 


$$
\rho=\rho_{0}\left(1+\frac{6.0 \times 10^{-10}\left(p_{h}-p_{a t m}\right)}{1+1.7 \times 10^{-9}\left(p_{h}-p_{a t m}\right)}\right)\left[1-0.65 \times 10^{-3}\left(\Theta-\Theta_{0}\right)\right]
$$

in which $p_{a t m}$ is the atmospheric pressure and $\Theta_{0}$ is temperature in $K$ (i.e. $\Theta_{0}=\theta_{0}+273$ ). Lubricant density at atmospheric pressure, $\rho_{0}$, is given in Table 2.

Variations of lubricant dynamic viscosity with pressure and temperature can be expressed based on Roelands' equation [29] and further developed by Houpert [30], as follows:

$$
\eta=\eta_{0} \exp \left\{\left(\ln \left(\eta_{0}\right)+9.67\right)\left[\left(\frac{\Theta-138}{\Theta_{0}-138}\right)^{-S_{0}}\left(1+\frac{p_{h}-p_{a t m}}{1.98 \times 10^{8}}\right)^{Z}-1\right]\right\}
$$

in which, $\eta_{0}$ is the lubricant dynamic viscosity at atmospheric pressure and temperature, and $Z$ and $S_{0}$ are constants:

$$
Z=\frac{\alpha_{0}}{5.1 \times 10^{-9}\left[\ln \left(\eta_{0}\right)+9.67\right]} \quad \text { and } \quad S_{0}=\frac{\beta_{0}\left(\Theta_{0}-138\right)}{\ln \left(\eta_{0}\right)+9.67}
$$

where $\alpha_{0}$ and $\beta_{0}$ are constants at atmospheric temperature and pressure. Details of lubricant rheological parameters are given in Table 2. It should be noted that the rheological parameters are for fresh lubricant. In practice, the lubricant is subject to shear thinning, oxidation and contamination [31].

Table 2: Lubricant properties in atmospheric pressure and $40^{\circ} \mathrm{C}$

\begin{tabular}{|c|c|c|}
\hline Parameters & Values & Units \\
\hline Lubricant viscosity, $\eta_{0}$ & 0.05 & $\mathrm{~kg} / \mathrm{m}-\mathrm{s}$ \\
\hline Lubricant density, $\rho_{0}$ & 833 & $\mathrm{~kg} / \mathrm{m}^{3}$ \\
\hline Lubricant specific heat, $C_{p}$ & 1968 & $\mathrm{~J} / \mathrm{kg}-\mathrm{K}$ \\
\hline Lubricant thermal conductivity, $k$ & 0.145 & $\mathrm{w} / \mathrm{m}-\mathrm{K}$ \\
\hline$\alpha_{0}$ & $1 \times 10^{-8}$ & $\mathrm{~m}^{2} / \mathrm{N}$ \\
\hline$\beta_{0}$ & $4 \times 10^{-2}$ & - \\
\hline
\end{tabular}

\subsection{Heat generation and thermal boundary conditions}


(Accepted Version)

Lubricant temperature rises due to internal friction. In the Navier-Stokes approach, solving the energy equation (10) with the appropriate boundary conditions provides a prediction of heat generated in the contact conjunction due to viscous shear. However, temperatures of contacting surfaces also increase with the rising contact temperature of the lubricant. Therefore, temperature boundary conditions are themselves a function of internal heat. For the liner the measured temperature, using a thermocouple very close to the sliding surface, is used as shown in Figure 3. Therefore, instantaneous temperature boundary condition for the liner is that measured. The compression ring temperature is obtained through internal heat partitioning, thus is not adiabatic. To obtain the temperature rise of the bounding surfaces, a thermal heat transfer partitioning model needs to be used which takes into account the transferred heat to the contacting surfaces (boundaries) as well as the heat which is carried away by the lubricant flow though the contact. Morris et al [4] have described an analytical model, based on a control volume approach which takes into account the local temperature rise on the contacting surfaces due to conduction from the lubricant and also direct asperity contacts. The method described by Morris et al [4] is also adopted here in conjunction with the Navier-Stokes analysis.

In the thermal heat transfer model, at any instant of time, corresponding to a crank angle position, the equality of inlet and outlet flows is maintained. This is an outcome of the instantaneous quasi-static equilibrium at any given crank angle. However, the flow rate is subject to change between subsequent crank angle positions as the variations of the film thickness with time $\left(\frac{\partial h}{\partial t}\right)$ is taken into account. In addition, there is a convection thermal flux at the inlet nib to the conjunction from the solid boundaries to the entrant lubricant supply at a lower temperature $\theta_{i n}$. This raises the inlet lubricant to $\theta_{0}$ from its assumed bulk flow temperature (inlet heating):

$$
\theta_{0}=\frac{\theta_{s 1} U_{1}+\theta_{s 2} U_{2}}{U_{1}+U_{2}}
$$

where $\theta_{s 1}$ and $\theta_{s 2}$ are the initial surface temperatures of the bore/liner and ring surface. Since one of the surfaces is stationary, therefore from equation (23), $\theta_{0}=\theta_{s 1}$ at the inlet due to the convective thermal flux. The liner temperature is measured from the engine liner surface and, therefore, is known a priori at any given crank angle location (see Figure 3). 


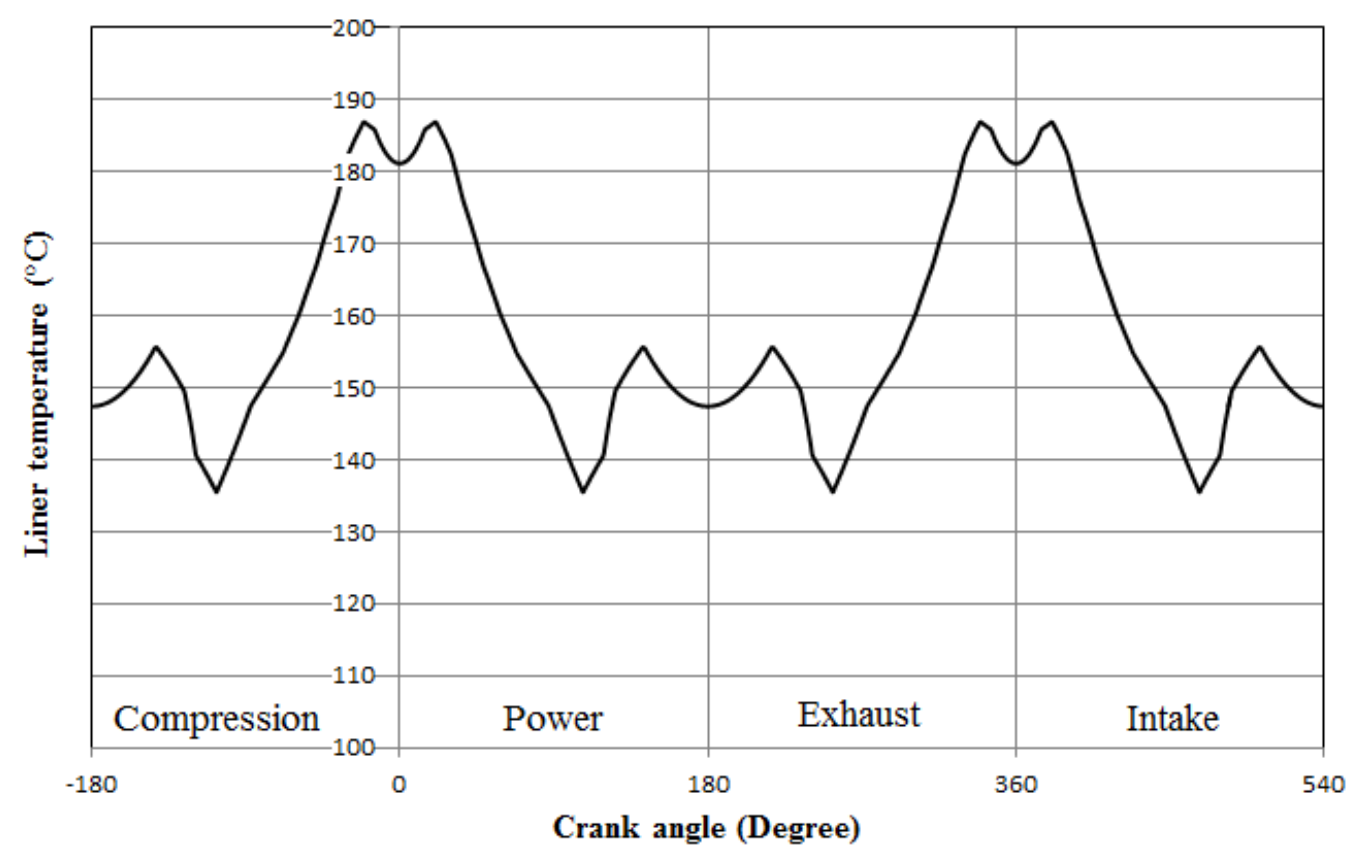

Figure 3: The temperature of the liner at the ring contact location throughout the engine strokes

The oil temperature distribution obtained through solution of energy equation (10) is based upon an initially assumed temperature for the ring surface. Therefore, the heat partitioning method described by Morris et al [4] can predict the quantity of heat transfer from the ring, contributing to the rise in its temperature when considering the heat removal through convection cooling by the lubricant, flowing through the contact exit (see Figure 4).

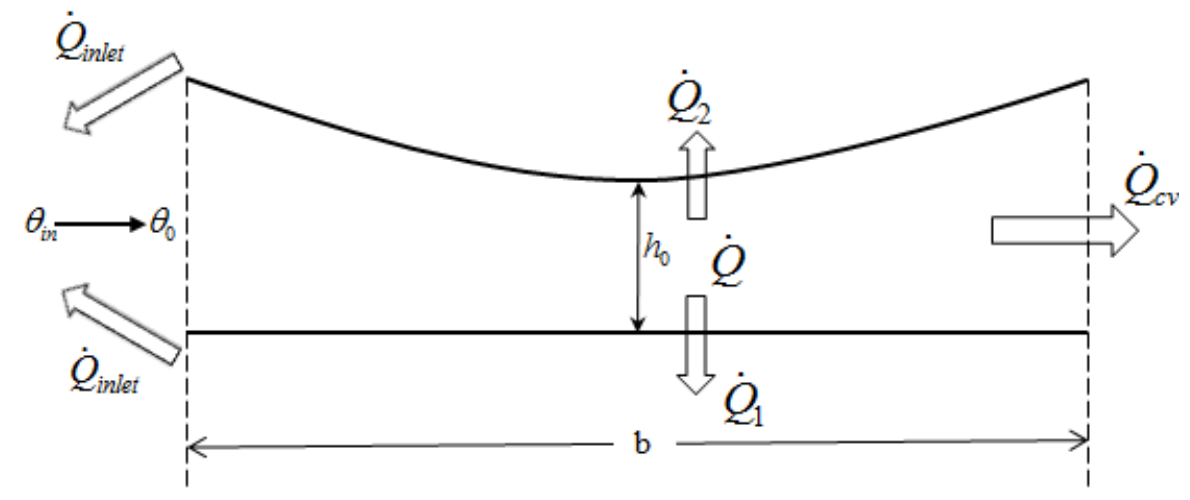

Figure 4: Thermal flow within the contact (Morris et al [4]) 
Since the thermal model is a control-volume based approach, the effective temperature of the lubricant, obtained from solving equation (10) is averaged throughout the contact as:

$$
\theta_{e}=\frac{\int_{0}^{b} \int_{0}^{h(x)} \theta(x, z) d z d x}{\int_{0}^{b} \int_{0}^{h(x)} d z d x}
$$

The rise in the ring surface temperature is obtained from the following relationship (Morris et al [4]):

$$
\Delta \theta_{s 2}=\frac{R_{f}}{R_{l}+R_{v}+R_{f}}\left(\theta_{e}-\theta_{s 2}\right)
$$

in which, $\theta_{s 2}$ is the initial ring surface temperature and $R_{l}, R_{v}$ and $R_{f}$ are the thermal resistances associated with conduction through the lubricating film, convective heat transfer through the boundary layer and the rise in the solid surface flash temperature respectively (Olver and Spikes [32]). These parameters were calculated according to the given relationships in Morris et al [4]. In addition, ring and liner mechanical/thermal properties are provided in Table 3, Section 3.7.

\subsection{Asperity interaction}

The share of load carried by the interacting asperities in the contiguous is obtained as [5]:

$$
W_{a}=\frac{16 \sqrt{2}}{15} \pi(\zeta \kappa \sigma)^{2} \sqrt{\frac{\sigma}{\kappa}} E^{*} A F_{5 / 2}(\lambda)
$$

The dimensionless group $\zeta \kappa \sigma$ is known as the roughness parameter, whilst $\sigma / \kappa$ is a measure of a typical asperity slope. These can be obtained through topographical measurements. $E^{*}$ is the composite elasticity modulus and it is obtained as:

$$
\frac{1}{E^{*}}=\frac{1-v_{1}^{2}}{E_{1}}+\frac{1-v_{2}^{2}}{E_{2}}
$$

where $v_{1}$ and $v_{2}$ are the Poisson's ratios, and $E_{1}$ and $E_{2}$ the moduli of elasticity for the materials of bounding solid surfaces. The statistical function $F_{5 / 2}(\lambda)$ is introduced to match the assumed Gaussian distribution of asperities as a function of the Stribeck oil film parameter, $\lambda=h / \sigma$. 


\section{(Accepted Version)}

Using a fifth-order polynomial curve fit this statistical function can be described as [5]:

$$
F_{5 / 2}(\lambda)=-0.0046 \lambda^{5}+0.0574 \lambda^{4}-0.2958 \lambda^{3}+0.7844 \lambda^{2}-1.0776 \lambda+0.6167
$$

Table 3 lists the material properties as well as the surface topographical parameters for both the compression ring and the liner samples used in this analysis.

Table 3: Material properties and surface topographical parameters

\begin{tabular}{|c|c|c|}
\hline Parameters & Values & Units \\
\hline Liner material & Grey cast iron & - \\
\hline Modulus elasticity of liner material & 92.3 & $\mathrm{GPa}$ \\
\hline Poisson ratio for liner material & 0.211 & - \\
\hline Density for liner material & 7200 & $\mathrm{Kg} / \mathrm{m}^{3}$ \\
\hline Thermal conductivity for liner material & 55 & $\mathrm{~W} / \mathrm{m} . \mathrm{K}$ \\
\hline Specific heat capacity for liner material & 460 & $\mathrm{~J} / \mathrm{Kg} . \mathrm{K}$ \\
\hline Ring material & Steel SAE 9254 & - \\
\hline Modulus elasticity of ring material & 203 & $\mathrm{GPa}$ \\
\hline Poisson ratio for ring material & 0.3 & - \\
\hline Roughness parameter $(\zeta \kappa \sigma)$ & 0.04 & - \\
\hline Measure of asperity gradient $(\sigma / \kappa)$ & 0.001 & - \\
\hline Density for ring material & 7700 & $\mathrm{Kg} / \mathrm{m}^{3}$ \\
\hline Thermal conductivity for ring material & 25 & $\mathrm{~W} / \mathrm{m} . \mathrm{K}$ \\
\hline Specific heat capacity for ring material & 460 & $\mathrm{~J} / \mathrm{Kg} . \mathrm{K}$ \\
\hline
\end{tabular}

\subsection{Conjunctional friction}

At any instant of time, viscous shear of a film of lubricant, $h$, is obtained as [1]

$$
\vec{\tau}=\left| \pm \frac{h}{2} \nabla p-\Delta \vec{V} \frac{\eta}{h}\right|
$$


If this shear stress is below the limiting Eyring [33] shear stress of the lubricant used; $\tau_{0}=2 \mathrm{MPa}$ (in this case), then, the lubricant follows a Newtonian shear behaviour, and friction is obtained as $f_{v}=\tau A$, where $A=2 \pi r_{0} b$ is the apparent contact area.

Under the mixed elastohydrodynamic analysis and at high shear, the lubricant film is usually quite thin and subject to non-Newtonian traction $\left(\tau>\tau_{0}\right)$ at the tip of asperities [1]. The total friction is, therefore, a summation of viscous shear of the lubricant and boundary contribution due to asperity interactions on the contiguous surfaces:

$$
f_{t}=f_{v}+f_{b}
$$

The boundary friction is obtained as [34]

$$
f_{b}=\tau_{0} A_{a}+\mu W_{a}
$$

where $\mu$ is the pressure coefficient for boundary shear strength of asperities on the softer counterface. A value of $\mu=0.17$ for ferrous-based surfaces was chosen. In addition, the cumulative area of asperity tips, $A_{a}$, is found as [34]

$$
A_{a}=\pi^{2}(\zeta \kappa \sigma)^{2} \sqrt{\frac{\sigma}{\kappa}} A F_{2}(\lambda)
$$

where $F_{2}(\lambda)$ is a function representative of the Gaussian distribution of asperities in terms of $\lambda$ (the Stribeck oil film parameter) [5]:

$$
F_{2}(\lambda)=-0.0018 \lambda^{5}+0.0281 \lambda^{4}-0.1728 \lambda^{3}+0.5258 \lambda^{2}-0.8043 \lambda+0.5003
$$

The viscous friction force, $f_{v}$ is obtained as:

$$
f_{v}=\tau\left(A-A_{a}\right)
$$

The total power loss from ring-bore conjunction is because of both viscous and boundary contributions to the overall friction. The power loss due to boundary friction is:

$$
P_{f b}=f_{b} . U
$$

Therefore, the total friction loss is $P_{f}=P_{f b}+P_{f v}$. 
(Accepted Version)

\section{Solution Procedure}

A 2D simulation model is developed using the CFD package FLUENT 14.0. The preprocessor ANSYS Design Modeller and Meshing is used for the grid generation. The geometrical nature of the problem examined here (the film thickness is very small compared with bore radius) imposes the use of only quadrilateral cells. After conducting a grid sensitivity test on the accuracy of predictions, forty divisions were employed across the film thickness and 1,500 divisions along the ring face-width, thus a mesh of 60,000 cells. Calculation of Reynolds number for the studied conditions showed that the flow is well within the laminar region. The operating pressure and vaporization (cavitation) pressure are set to the atmospheric pressure of $101.3 \mathrm{kPa}$.

Pressure inlet and outlet boundary conditions are used for the leading and trailing edges of the ring/liner contact. Therefore, when the piston undergoes upstroke motion, the inlet pressure is that of the combustion chamber as given in Figure 5, whilst at the exit the crankcase pressure is assumed, which also is assumed to be the atmospheric pressure. On the other hand, for the down-stroke sense of the piston, the inlet pressure is set to that of the crank-case (atmospheric) pressure, whilst the outlet pressure is that of the combustion chamber. The chamber (combustion) pressure varies with engine stroke, speed and throttle demand. Figure 5 shows the in-cylinder pressure for the engine speeds of 1500 and $6000 \mathrm{rpm}$ with 63\% throttle. 


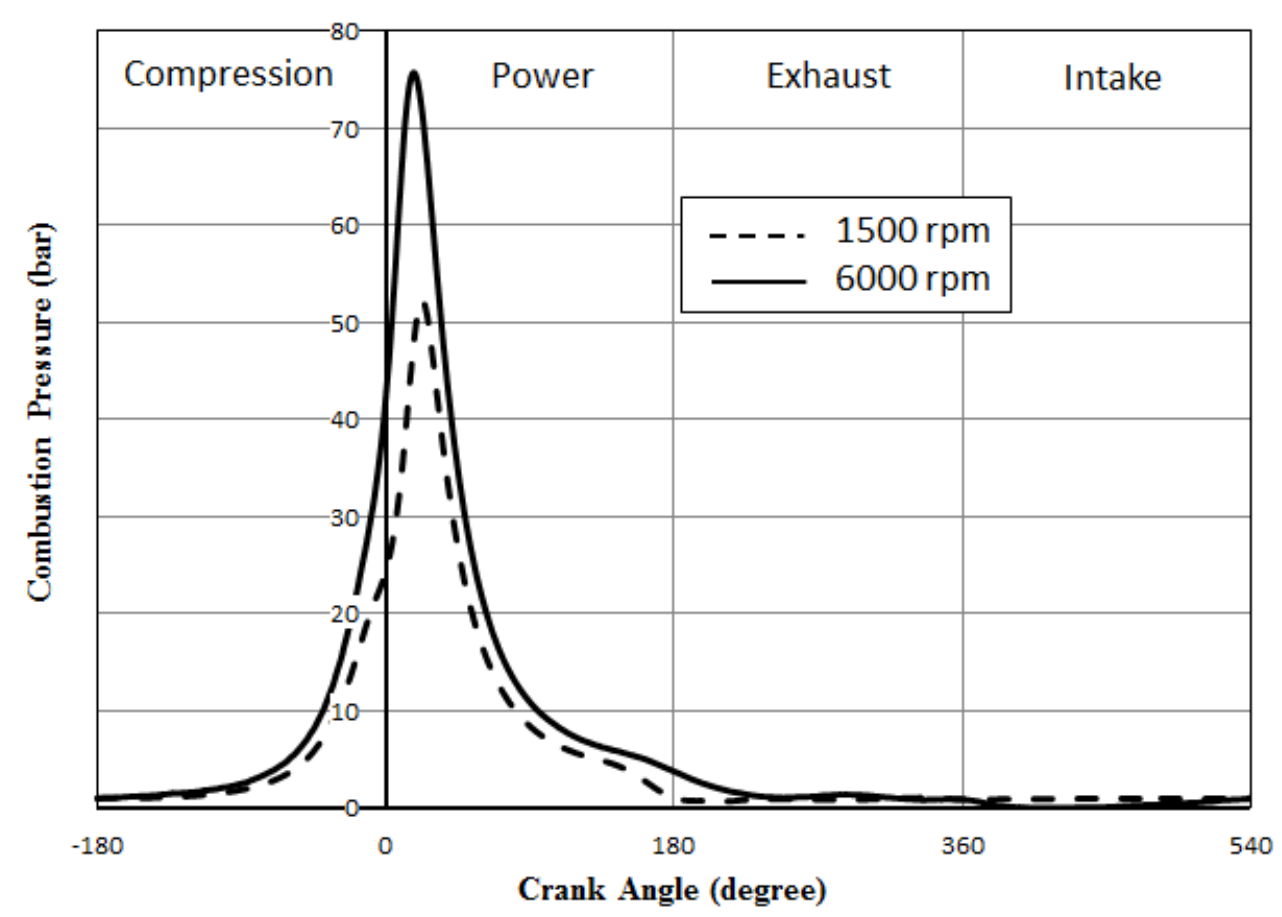

Figure 5: Variation of chamber pressure with crank angle for engine speeds of 1500 and $6000 \mathrm{rpm}$

The pressure-based mixture model [35] is chosen for the present CFD analysis. The velocitypressure coupling is treated using the SIMPLE algorithm and the second-order upwind scheme is used for the momentum to reduce the discretisation-induced errors in the calculations. For greater accuracy, a value of $10^{-6}$ is used for the all residual terms.

For solution of Elrod's cavitation model is an analytical method, originally described by Sawicki and $\mathrm{Yu}$ [36]. However, the method is modified to include the variations of viscosity and density/bulk modulus with pressure and temperature, using the equations given in Section 3.5. Once the pressure distribution is obtained either from CFD analysis or the Elrod's method, it is integrated over the contact area to obtain the hydrodynamic reaction (see equation (5)).

The solution procedure is as follows:

Step 1: At a given crank angle, calculate the total force exerted on the ring due to combustion gas pressure and ring elastic force (equations (3) and (4)).

Step 2: Assuming an initial value for the minimum film thickness, lubricant film temperature and pressure distribution, and the lubricant bulk rheological properties are calculated. In addition, an initial value for the ring surface temperature is assumed. 
(Accepted Version)

Step 3: The contact pressure distribution is obtained using two-phase flow CFD analysis described in Sections 3.1 and 3.2, or the Elrod's cavitation model described in Section 3.3.

Step 4: The predicted pressures are used to update the rheological properties and Step 3 is repeated until the pressure in the Elrod's method in two successive iteration steps remains within the stated convergence criterion. It is noted that in the CFD approach the lubricant rheological properties are updated internally for the generated pressure and temperature distributions as the solution proceeds. In addition, using the heat partitioning model described in Section 3.6, the rise in the ring surface temperature is also calculated.

Step 5: The load carried by asperities is calculated using equation (26).

Step 6: The pressure distribution is used to obtain the hydrodynamic reaction. Since the method of solution is quasi-static, this conjunctional reaction together with the asperitycarried load should support the total applied load exerted by the gas and ring elastic forces at each crank angle. The quasi-static balance of applied forces on the ring is sought through:

$\operatorname{Err}_{\text {load }}=\frac{|F(\varphi)-W(\varphi)|}{F(\varphi)} \leq 1.0 \times 10^{-3}$

where $\operatorname{Err}_{\text {load }}$ is the error in the load balance condition. If this criterion is not met, then, the minimum film thickness is updated using the following equation:

$h_{m}^{n}=(1+\delta \mathrm{X}) h_{m}^{o}$

where $\mathrm{X}$ is an adjusting parameter, $\mathrm{X}=F(\varphi)-W(\varphi) / \max \{F(\varphi), W(\varphi)\}$. Superscripts $n$ and $o$ denote new and old steps in the iteration process. A damping coefficient $\delta=0.05$ is used to achieve faster load convergence, whilst maintaining numerical stability. It is noted that the 'dynamic mesh' concept [37] is employed for variations in the minimum film thickness in the CFD analysis. In this method, the corresponding user-defined function (UDF) determines the desired position of the ring using the dynamic mesh technique. To achieve this, a smoothing mesh method is used with a convergence tolerance of $10^{-5}$.

With a new value for the minimum film thickness, the Steps 2 to 6 are repeated until the convergence criterion in Step 6 is met.

Step 7: Calculate the corresponding viscous and boundary friction contributions, and hence the total friction, using equations (34), (31) and (30). Then, proceed to the next crank angle, repeating all the above steps. 


\section{Results and Discussion}

\subsection{Pressure distributions in isothermal condition}

As the first step, it would be interesting to note the validity of the CFD approach developed here. A good comparison can be made with the Elrod's approach, which is traditionally used for such tribological contacts. Furthermore, an isothermal analysis somewhat simplifies the problem.

Figures 6-8 present the results for axial pressure profiles along the ring face-width at crankangles: $\pm 1^{\circ}, \pm 21^{\circ}$ and $\pm 90^{\circ}$ under assumed isothermal conditions. The predictions are made by two different methods: (I) Two-phase flow Navier-Stokes equations and (II) the Elrod's modified approach to Reynolds equation. Good agreement is observed in all cases. Note that the crank-angle of $0^{\circ}$ corresponds to the position of TDC in transition from the compression to the power stroke. The region bounded by the crank-angles $\pm 1^{\circ}$ corresponds to quite low speeds of entraining motion of the lubricant. Inlet reversals can be noted as the piston sense of motion alters (Figure 6a and b). Figure 7b corresponds to the detonation point, where the maximum combustion pressure occurs. The differences between the two methods of analysis emerge in Figures 7a, and 8a and b. These correspond to relatively lightly loaded contact conditions with higher speeds of entraining motion of the lubricant into the conjunction. These differences are as the result of outlet boundary conditions, which are clearly based on the film rupture point, beyond which cavitation region occurs. With the Elrod's approach there are prescribed contact outlet boundary conditions, which are based on the value of film ratio $\xi<1$. The CFD approach is based on open boundary condition (i.e. there is no prescriptive outlet boundary condition for the lubricant film rupture location). Since lightly loaded conditions with higher lubricant entraining velocity (in cases of $\varphi= \pm 90^{\circ}$, mid-span piston position) lead to film rupture and cavitation any prescriptive outlet conditions may be regarded as somewhat artificial. The difference is more significant in terms of friction than pressure distribution (see later). 
Tribology Letters, June 2013, DOI: 10.1007/s11249-013-0163-5

(Accepted Version)

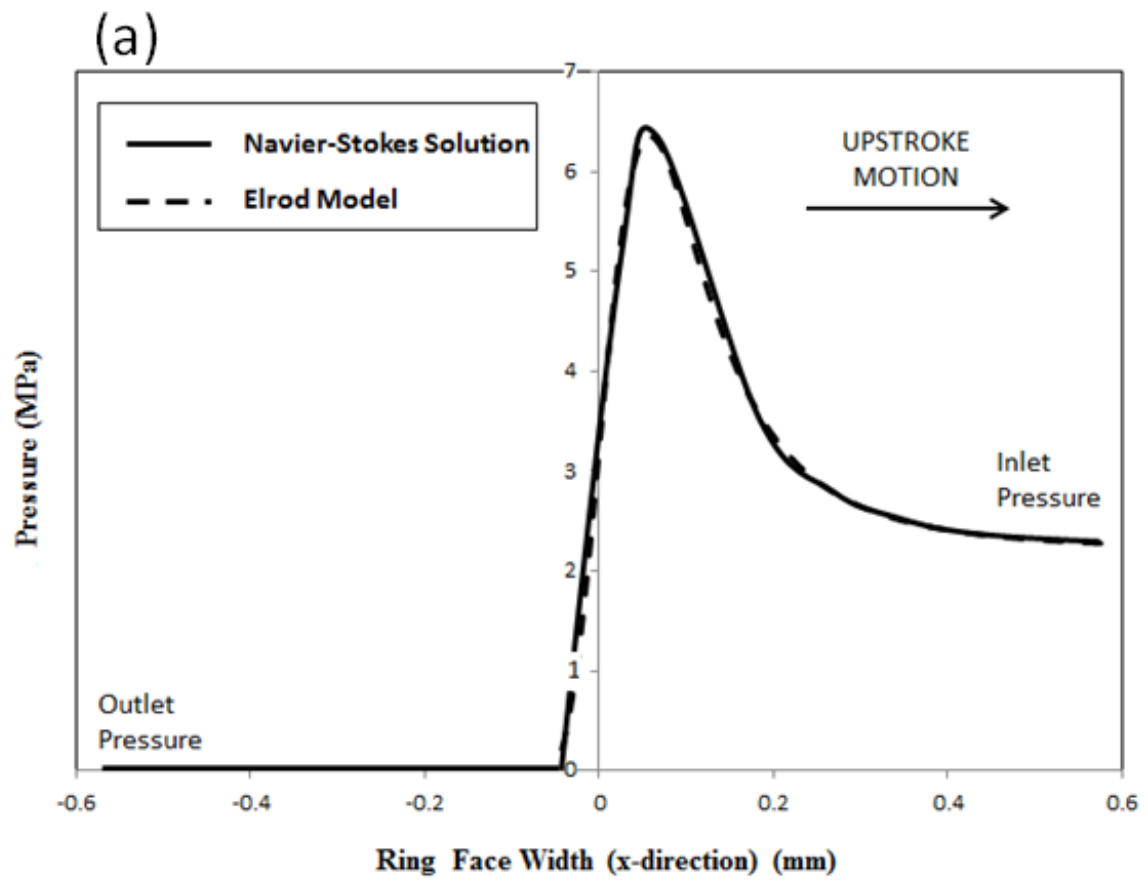

(b)

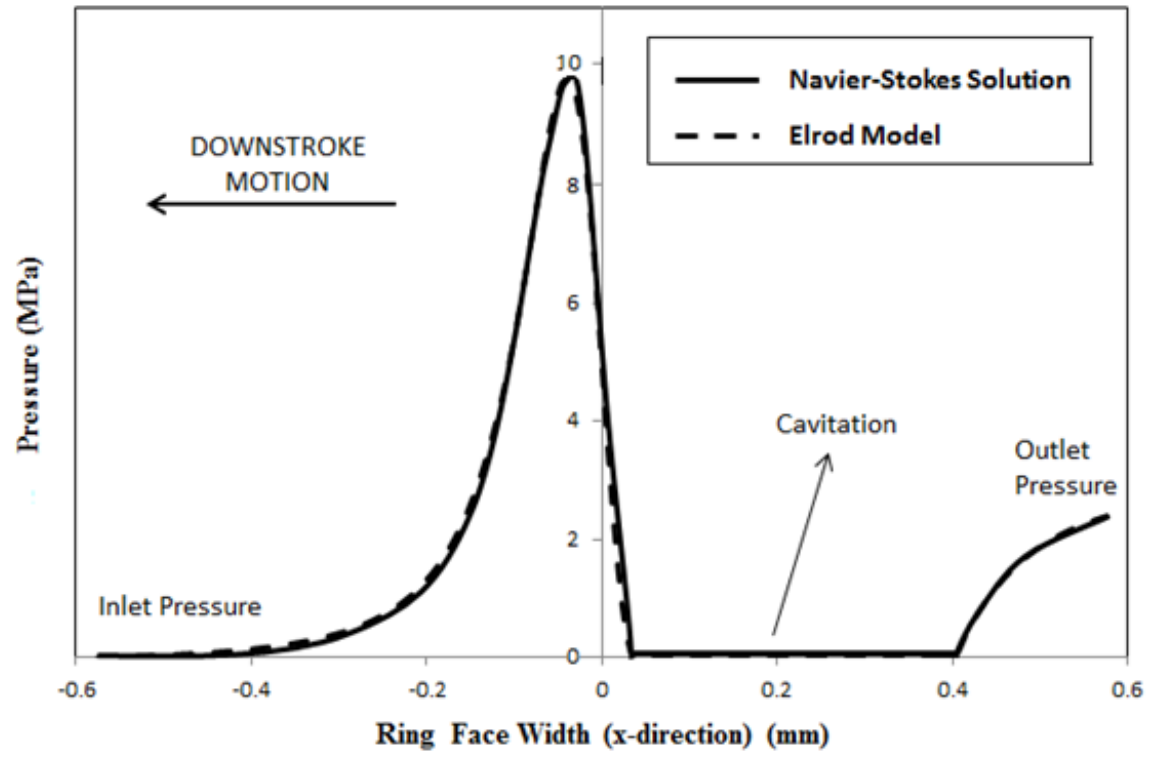

Figure 6: Pressure distribution along the ring face-width (x-direction) for (a) $\varphi=-1^{\circ}$ and (b) $\varphi=+1^{\circ}$, at engine speed of $1500 \mathrm{rpm}$ 
Tribology Letters, June 2013, DOI: 10.1007/s11249-013-0163-5

(Accepted Version)

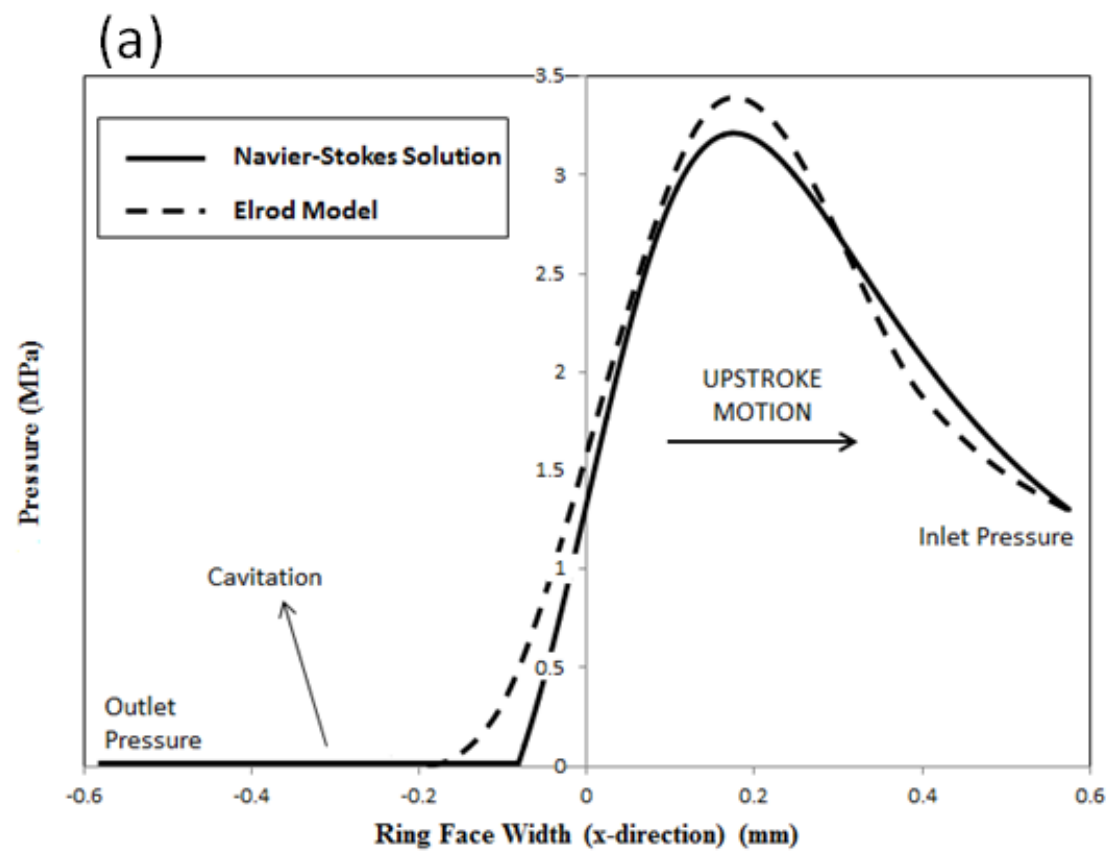

(b)

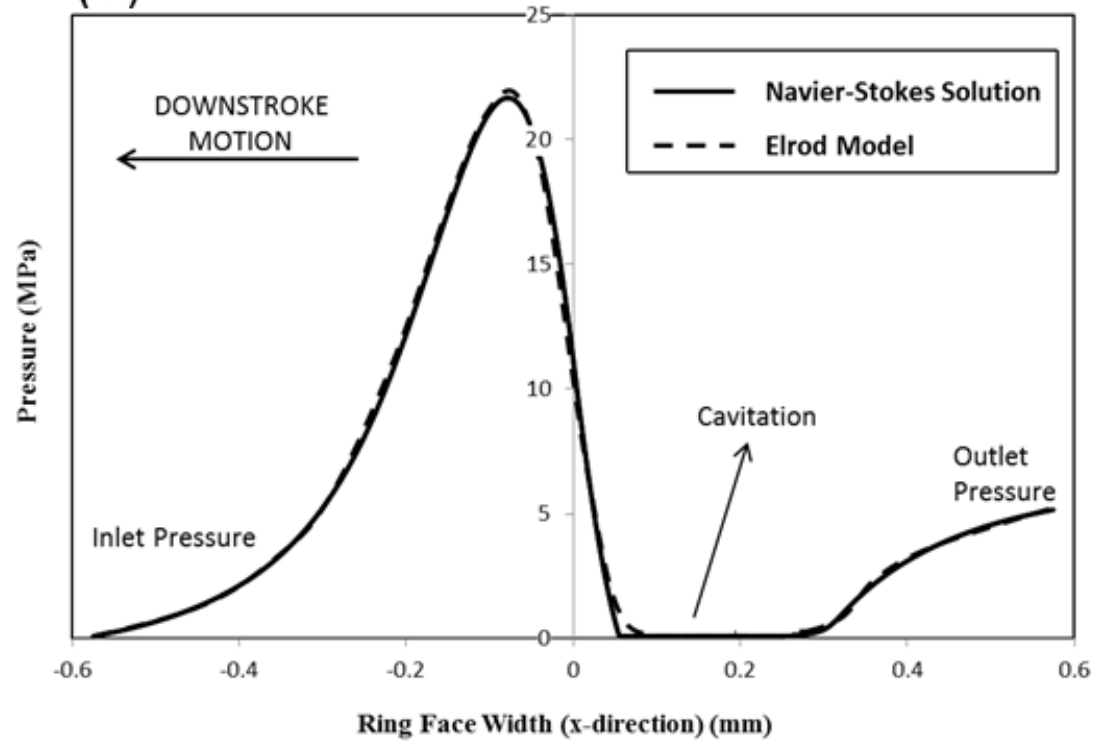

Figure 7: Pressure distribution along the ring face-width ( $x$-direction) for (a) $\varphi=-21^{\circ}$ (compression stroke prior to TDC) and (b) $\varphi=+21^{\circ}$ (detonation in power stroke), at engine speed of $1500 \mathrm{rpm}$ 
(a)

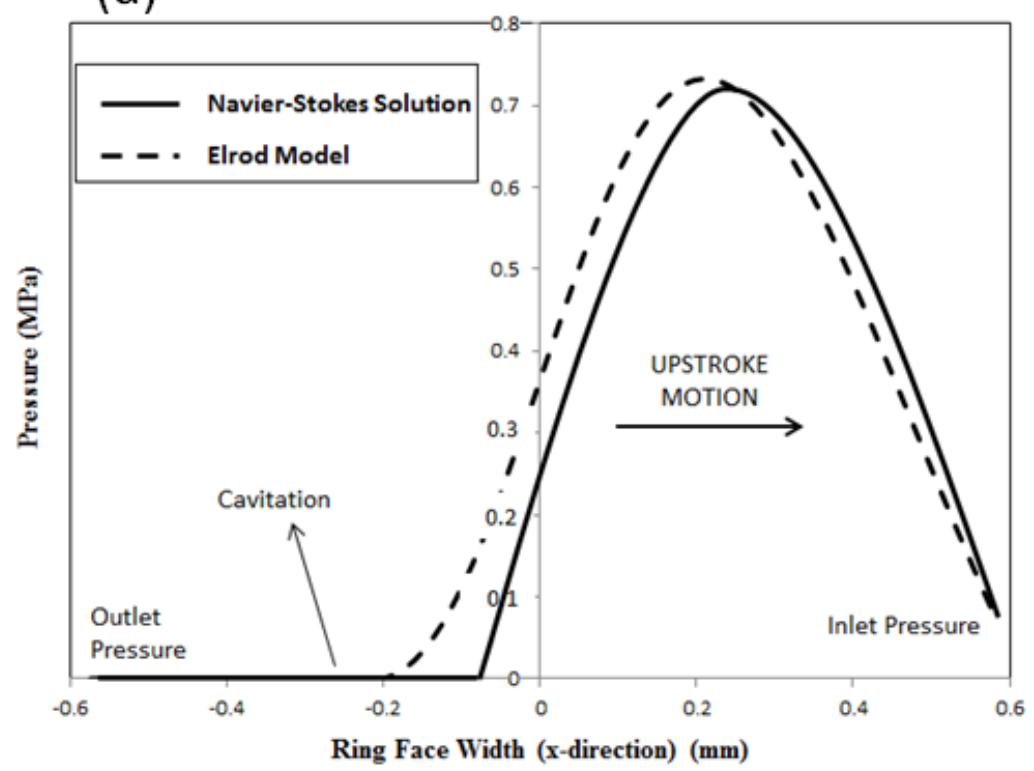

(b)

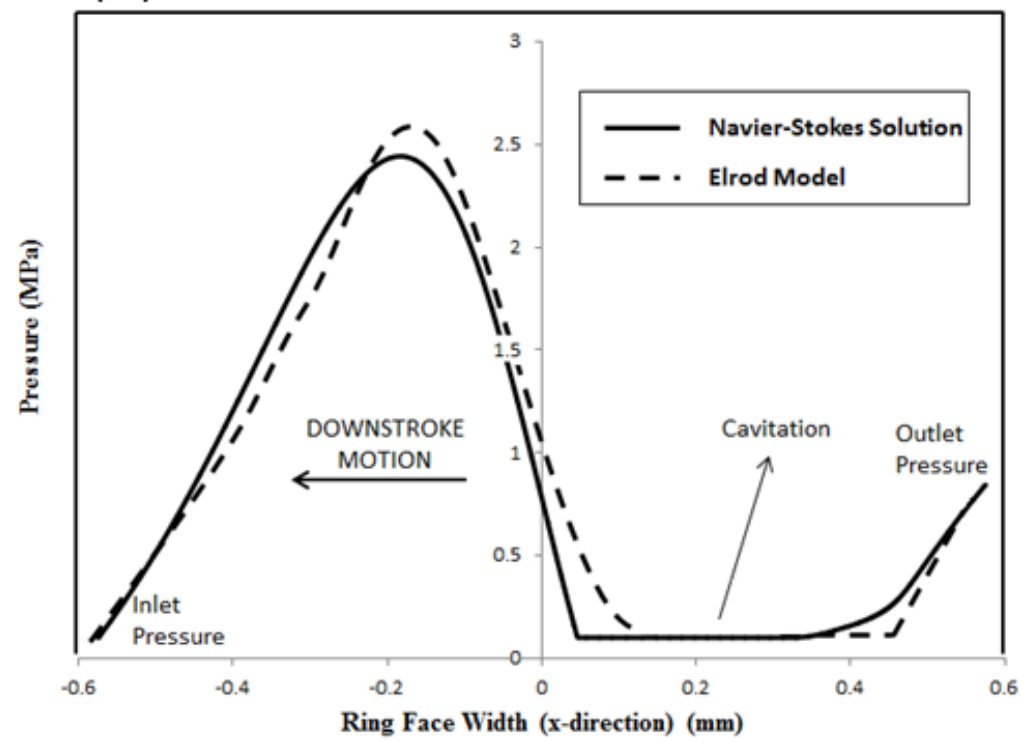

Figure 8: Pressure distribution along the ring face-width ( $x$-direction) for (a) $\varphi=-90^{\circ}$ ( $m i d$ compression stroke) and (b) $\varphi=+90^{\circ}$ (mid power stroke), at engine speed of $1500 \mathrm{rpm}$

\subsection{Minimum lubricant film thickness}

The key parameter predicted by the lubrication model is the cyclic variation in minimum film thickness. There is clearly a direct correlation between film thickness and friction. Therefore, it is particularly important to investigate parts of engine cycle where the film thickness is insufficient to guard against direct surface interactions. Figure 9 shows the CFD predicted 
(Accepted Version)

minimum film thickness variation for the parabolic ring profile at the engine speed of 1500 rpm in comparison with that predicted by the Elrod's model, both under assumed isothermal conditions. The results of these analyses are quite close. Both solutions exhibit the expected characteristic shape of the curve with instances of thin films occurring around the dead centre reversals, where the lubricant entrainment velocity is negligible. Sufficient film thickness exists at the mid-stroke positions, where there is adequate entrainment velocity. The thickness of lubricant film is generally thinner during the power stroke owing to the higher gas loading of the ring. The figure also includes the CFD predicted minimum film thickness variations for thermal condition at the same engine speed. With thermal effects taken into account, the film thickness is considerably reduced and the ring-bore conjunction resides in mixed or boundary regimes of lubrication for a significant proportion of the engine cycle. This is a more realistic result with regard to observed and measured friction, for instance by Furuhama and Sasaki [38] and Gore et al [39]. Therefore, the significant differences between isothermal and thermal analyses shown by Gosh and Gupta [40] is justified, but not often noted in much of the reported studies.

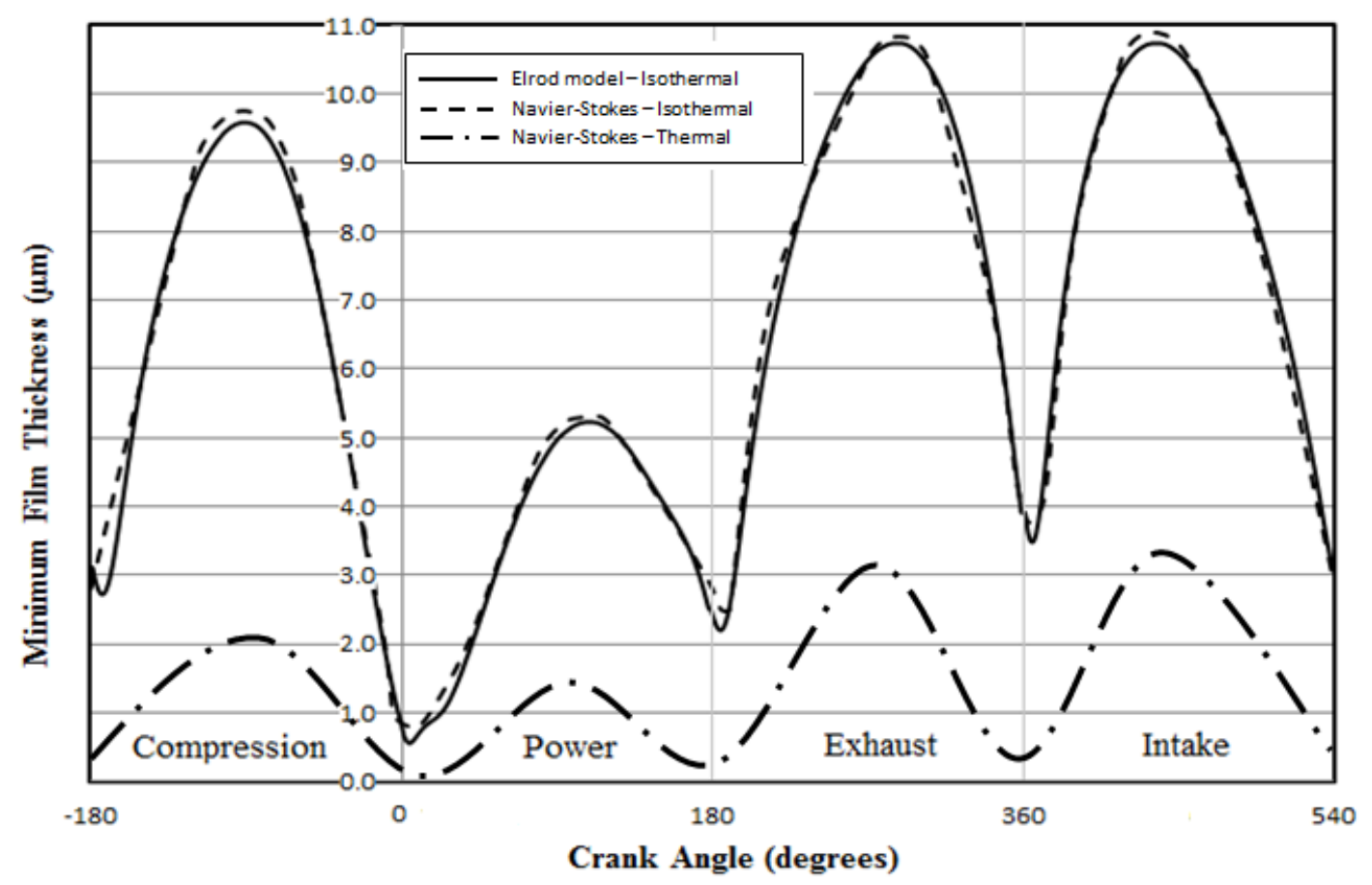

Figure 9: Minimum film thickness at engine speeds of $1500 \mathrm{rpm}$

\subsection{Prediction of Friction}




\section{(Accepted Version)}

Piston-cylinder friction is a dominant source of parasitic mechanical losses in IC engines, accounting for nearly $9 \%$ of the input fuel energy expended [41]. Therefore, one of the overriding industrial objectives is to predict frictional losses from all the conjunctions of the piston-cylinder system. Figure 10 shows the CFD predicted friction compared with the experimental measurements by Furuhama and Sasaki [38] from a 2 cylinder rig made from an 8-cylinder Chevrolet engine running at the engine speed of $1200 \mathrm{rpm}$. The other predictions in the figure are those by Mishra et al [12]. The CFD predictions conform well to the experimental results and are an improvement upon those of Mishra et al [12] which are isothermal and use Reynolds equation with Swift-Stieber exit boundary condition for the hydrodynamic contribution. The agreement is particularly striking for the power stroke and for the later stages of the compression stroke. There are some differences at mid-span in the power stroke. There seems to be more boundary interactions in the experimental results. This may well be because of bore out-of-roundness, thus some reduced clearance, which would be expected of all cylinder bores in practice. However, such data is not provided in [38]. The current analysis assumes a right circular cylindrical bore with circumferentially conforming ring-bore contact.

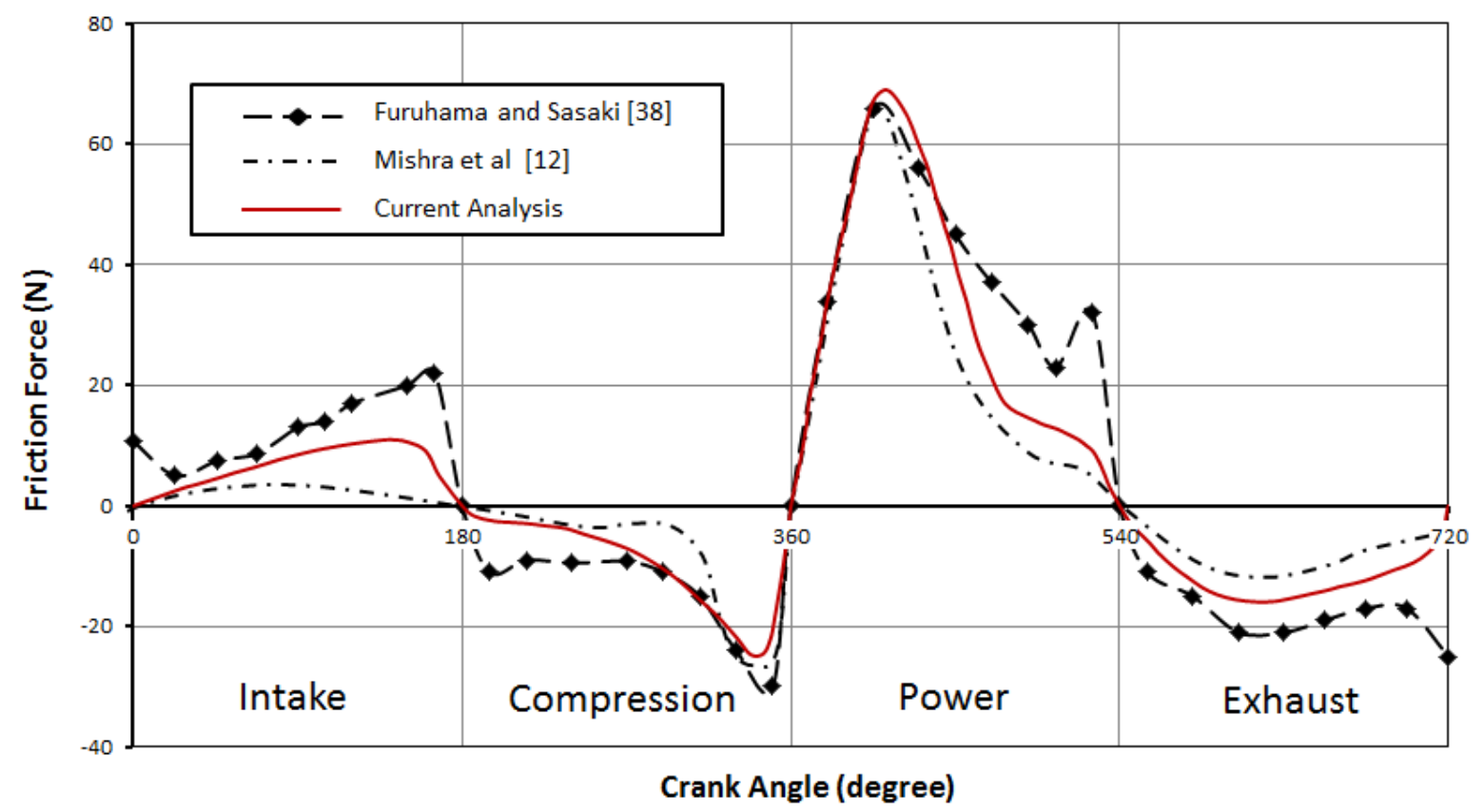

Figure 10: Comparison of current work with experimental measurements for friction force 
(Accepted Version)

Comparison of friction forces for isothermal and thermal cases is demonstrated in Figure 11. Note that the isothermal analysis would be representative of cold steady state condition, for example, similar to those at low engine speed emission tests defined by the NEDC (New European Drive Cycle) [42], where the lubricant viscosity used in the analysis corresponds to the temperature of $40^{\circ} \mathrm{C}$. Various regions of predicted engine cycle frictional characteristics are marked on the figure. Under isothermal (cold engine condition) viscous friction is generally higher because of a higher lubricant viscosity. Furthermore, the dominant source of viscous shear is Couette flow, which follows the piston sliding speed (second term in equation (29)). The exception is the region in transition from compression to the power stroke and extending past the detonation point. Under cold engine condition, it can be seen that the pure proportionality $\tau_{v} \propto U$ is lost in this region, because there is significant pressure loading of the ring conjunction (combustion curves in Figure 5). In this region lubricant action is dominated by Poiseuille shear (the first term in equation (29)).

The important point to note is that viscous friction, in general, is lower in the thermal case due to reduced lubricant viscosity. However, at the dead centre reversals, because of low entraining velocity the film thickness is significantly reduced (Figure 9), which leads to boundary interactions in the case of thermal case. This can be representative of hot steady state portion of the NEDC emission cycle [42]. The sharp rise rate in friction characteristics at dead centre reversals, due to mixed or boundary regime of lubrication, are also marked on Figure 11. In particular, the results show that friction at TDC reversal in transition from compression to the power stroke corresponds to a significant proportional of all cyclic frictional losses. 


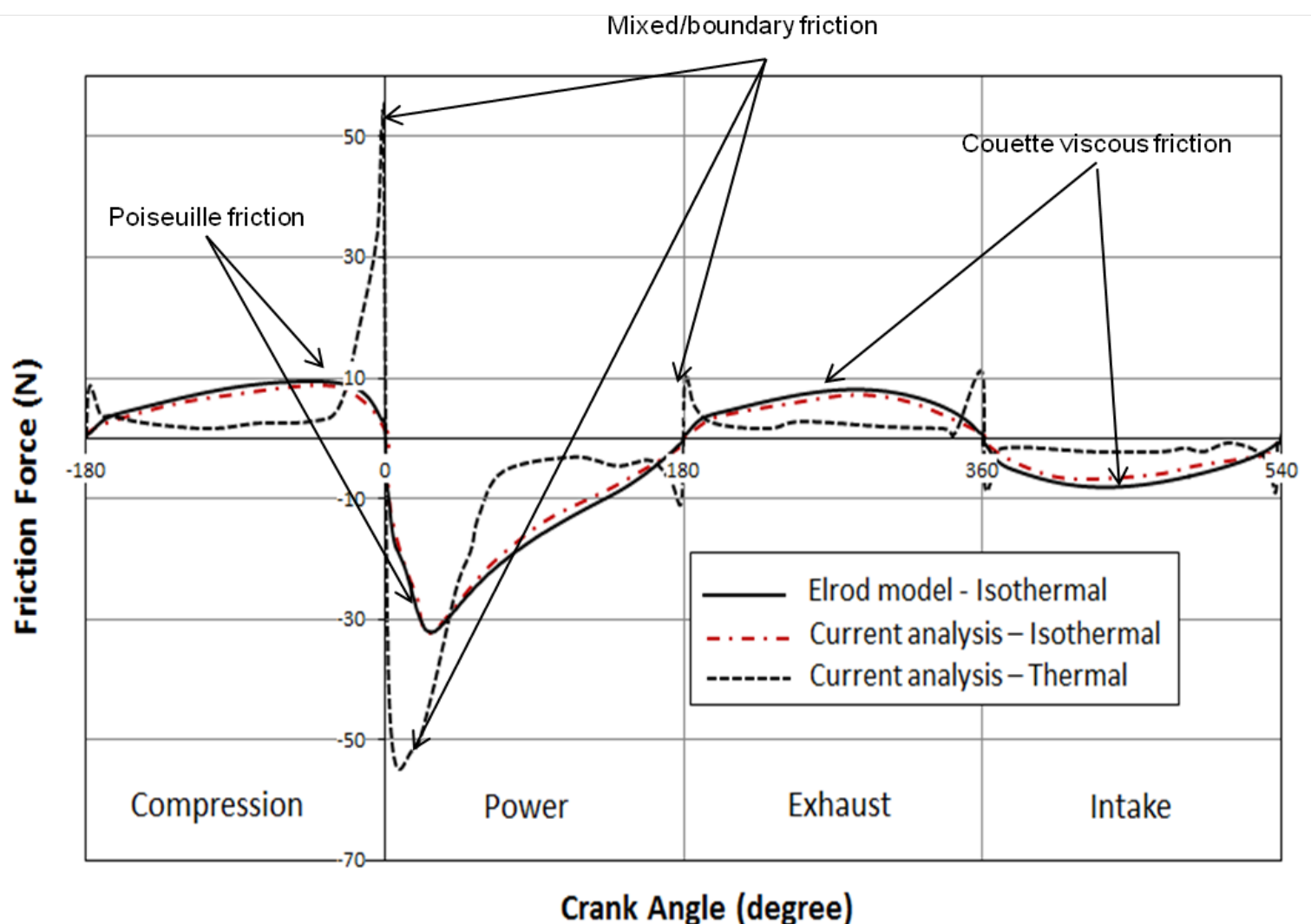

Figure 11: Predicted friction under isothermal and thermal conditions with CFD and Elrodtype analyses

\subsection{Fluid properties and flow parameters changes along depth of film}

Predictive methods based on Reynolds equation with appropriate boundary conditions, for example that of Elrod [16] or Sawicki and Yu [36] determine lubricant film rupture and reformation boundaries (Figure 1). The cavitation region is regarded to be contained within the contact zone, where $\xi<1$. However, as Reynolds equation assumes no pressure gradient through the thickness of the lubricant film due to its thinness (i.e. $d p / d z=0$ ), there is no prediction of disposition of the fluid phases. The use of Navier-Stokes equations with Rayleigh-Plesset equation and analytical control-volume thermal model, described here, enables the presence of fluid phases to be surmised according to void fraction as shown in Figure 12, in this case at the engine speed of $6000 \mathrm{rpm}$ and at crank angle of $90^{\circ}$. The choice of these conditions is because at higher piston sliding velocity and relatively lighter contact load a larger variation in fluid volume fraction results in the cavitation region as shown in Figure 12. With the Reynolds-based approaches, there is no significant contribution to 


\section{(Accepted Version)}

friction nor to the contact load carrying capacity as the cavitation region is assumed to remain under atmospheric conditions. In the Navier-Stokes equations, there exists some contribution due to the presence of a volume of liquid lubricant.

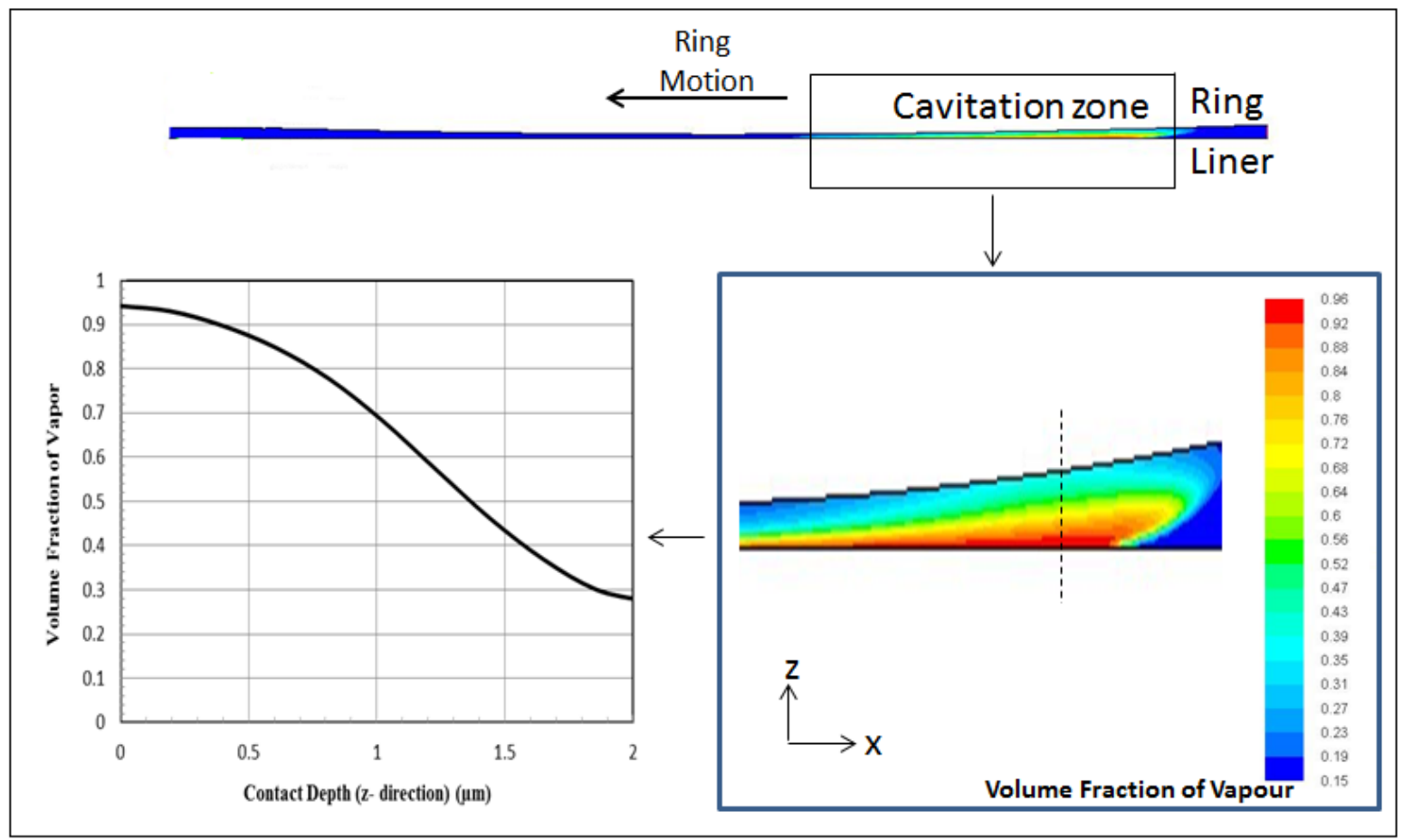

Figure 12: Changes of vapour volume fraction into the depth of the lubricant film at the crank angle position $90^{\circ}$ at the engine speed $6000 \mathrm{rpm}$ (cavitation zone, $x=0.2 \mathrm{~mm}$ )

Unlike other models, in the current CFD approach all operating and lubricant rheological parameters alter with the depth of the lubricant film. The changes of lubricant properties and flow parameters in the $z$ direction (film depth) for crank angle $90^{\circ}$ at engine speed $6000 \mathrm{rpm}$, in high pressure zone (region of full film, $x=-0.1 \mathrm{~mm}$ ) are plotted in Figures 13 and 14. The parametric variations show that the flow of lubricant through the contact may be viewed as layered streamlines at different rheological states. This means that in practice there would be internal friction and load carrying capacity contained within the streamlined flow, which would be more realistic than the idealised conditions belying Reynolds equation. 
Tribology Letters, June 2013, DOI: 10.1007/s11249-013-0163-5

(Accepted Version)

(a)

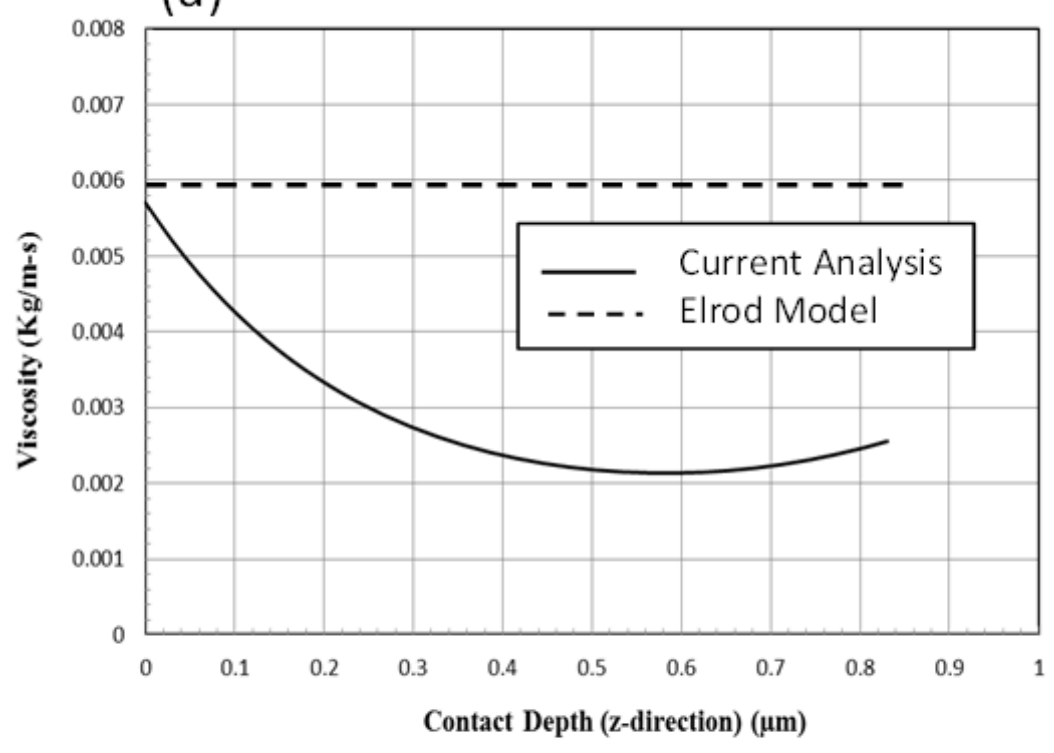

(b)

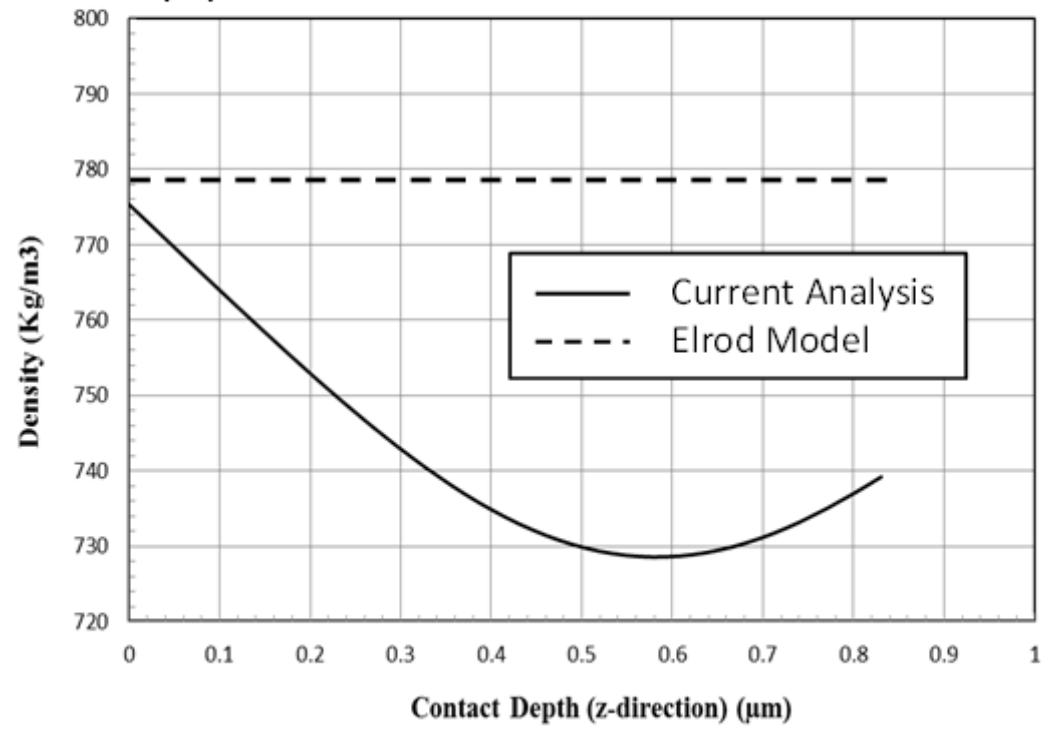

Figure 13: The changes in lubricant viscosity (a) and density (b) into the depth of the lubricant film at the crank angle of $90^{\circ}$ and engine speed of $6000 \mathrm{rpm}$ (full film region,

$$
x=-0.1 \mathrm{~mm})
$$


(a)

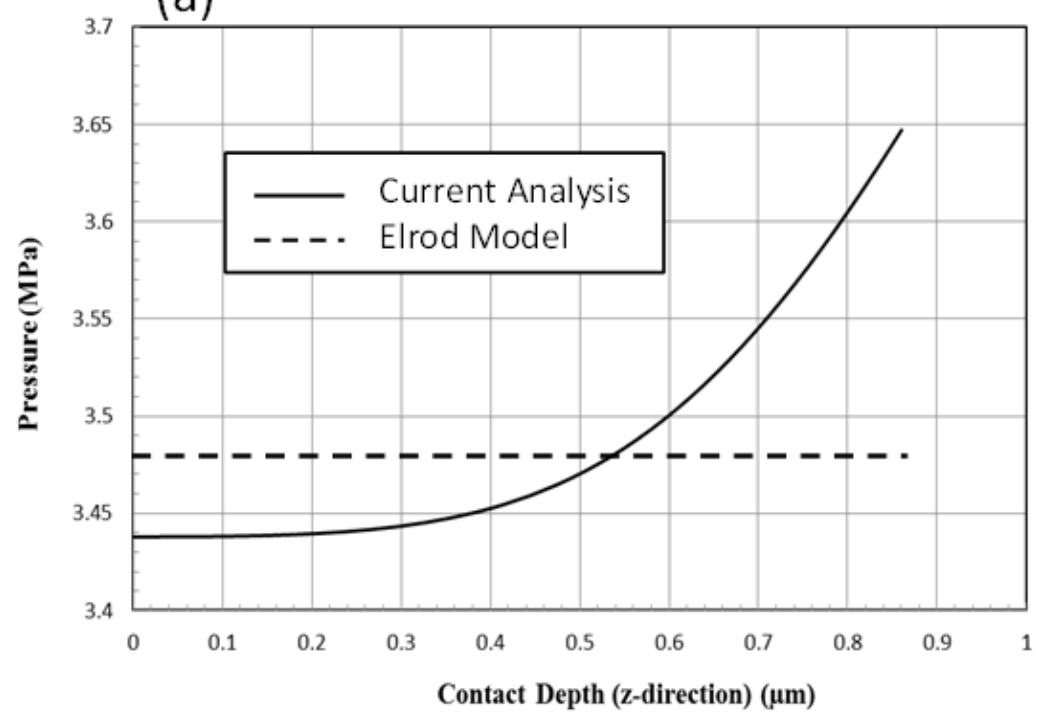

(b)

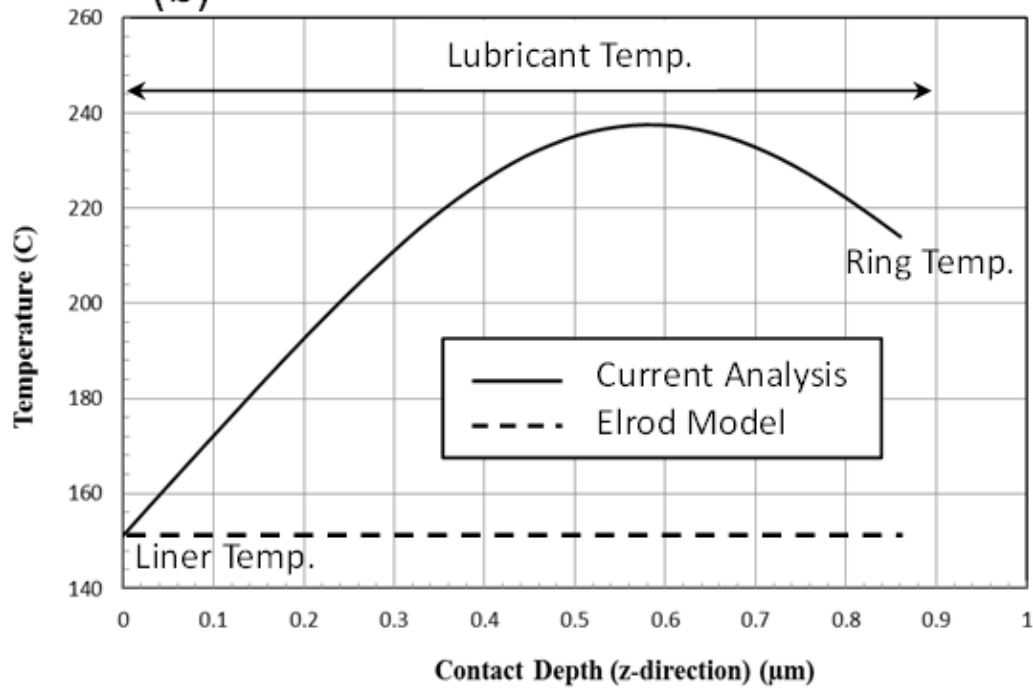

Figure 14: Changes in lubricant pressure (a) and temperature (b) in into the depth of the lubricant film at the crank angle of $90^{\circ}$ and engine speed of $6000 \mathrm{rpm}$ (full film region,

$$
x=-0.1 \mathrm{~mm})
$$

\section{Conclusions}

A new thermo-mixed hydrodynamic analysis method to study transient conditions in piston compression ring-cylinder liner conjunction is presented. The method makes use of NavierStokes equations, combined with Rayleigh-Plesset equation and analytical control-volume thermal model. It also incorporates the Greenwood and Tripp method to take into account the 
effect of asperity interactions in the region of thin films. This approach has not hitherto been reported in literature and highlights some important findings, when compared with the traditional approaches, such as Elrod's modification to Reynolds equation, based on the JFO boundary conditions.

Firstly, the lubricant flow may be envisaged as streamlined flow with variable layered potential energy contributing to load carrying capacity and internal friction. The layered characteristic flow leads to regions with varied volume fraction of vapour in the cavitation region of the contact. The exact disposition of vapour cavities in the form of bubbles and their flow dynamics would constitute the use of Lagrange-Euler method for discrete phases in the future extension of the current research.

Secondly, the results show that except at dead centre piston reversals, the underlying mechanism for friction is through viscous shear of the lubricant. This implies that reduced viscosity of the lubricant would be beneficial in reducing friction, if an alternative palliative measure can be identified to reduce the effect of boundary friction at piston TDC reversal particularly in transition from compression to power stroke. However, reducing lubricant viscosity cannot be accommodated because the same engine oil flows through the higher load intensity contacts such as the cam-follower pair, where high loads necessitate use of lubricants which have sufficient load carrying capacity; i.e. high viscosity. Palliative action at the TDC may be achieved through fabrication of surface textured reservoirs as shown by Rahnejat et al [43] and Ryk and Etsion [44]. However, this action may lead to oil loss and lubricant degradation in fully flooded parts of the engine cycle. The current analysis indicates that in the lightly loaded parts of the engine cycle at high sliding speeds regions of cavitation may occupy these intended textured reservoirs and reduce the load carrying capacity of the contact. Further investigation of these effective micro-bearing would be required with the approach expounded in the current analysis.

\section{Acknowledgements}

The authors would like to express their gratitude to the Lloyd's Register Educational Foundation (LREF) for the financial support extended to this research. Thanks are also due to the Engineering and Physical Sciences Research Council (EPSRC) for the Encyclopaedic Program Grant; some of research findings of which are used in this paper. 


\section{References}

[1] Gohar, R., and Rahnejat, H.: Fundamentals of Tribology. Imperial College Press (2008) [2] Andersson, B.S.: Company's Perspective in Vehicle Tribology-Volvo. Tribology Series (Elsevier), Vehicle Tribology 18, 503-506 (1991)

[3] Richardson, D.E.: Review of power cylinder friction for diesel engines. Trans ASME, $J$. Trib. 122, 506-519 (2000)

[4] Morris, N., Rahmani, R., Rahnejat, H., King P.D., Fitzsimons, B.: The influence of piston ring geometry and topography on friction. Proc. IMechE, Part J: J. Engng. trib. (2012), DOI: $10.1177 / 1350650112463534$

[5] Rahmani, R., Theodossiades, S., Rahnejat, H., Fitzsimons B.: Transient elastohydrodynamic lubrication of rough new or worn piston compression ring conjunction with an out-of-round cylinder bore. Proc. IMechE, Part J: J. Engng. trib. 226, 284-305 (2012)

[6] Ma, M. T., Sherrington, I., Smith, E. H.: Implementation of an Algorithm to Model the Starved Lubrication of a Piston Ring a Distorted Bores: Prediction of Oil flow and Onset of Gas Blow-by. Proc. IMechE, Part J: J. Engng. Trib. 210, 29-44 (1996)

[7] Jeng, Y.: Theoretical Analysis of Piston Ring Lubrication-Part I: Fully Flooded Lubrication. Trib. Trans. 35, 696-706 (1992)

[8] Jeng, Y.: Theoretical Analysis of Piston Ring Lubrication-Pan 11: Starved Lubrication and Its Application to a Complete Ring Pack. Trib. Trans. 35, 707-714 (1992)

[9] Ma, M. T., Sherrington, I., Smith, E. H.: Analysis of lubrication and friction for a complete piston-ring pack with an improved oil availability model, Part I: Circumferentially uniform film. Proc. IMechE, Part J: J. Engng. Trib. 211, 1-15 (1997)

[10] Akalin, O., Newaz, G.M.: Piston ring-cylinder bore friction modeling in mixed lubrication regime: Part II-Correlation with bench test data. Trans. ASME, J. Trib. 123, 219223 (2001)

[11] Mishra, P.C., Balakrishnan, S., Rahnejat, H.: Tribology of compression ring-to-cylinder contact at reversal. Proc. IMechE, Part J: J. Engng. Trib. 222, 815-826 (2008)

[12] Mishra, P.C., Rahnejat, H. and King, P.D.: Tribology of the ring-bore conjunction subject to a mixed regime of lubrication. Proc. IMechE, Part C: J. Mech. Engng. Sci., 223, 987-998 (2009)

[13] Bolander, N.W., Steenwyk, B.D., Sadeghi, F., Gerber, G.R.: Lubrication regime transitions at the piston ring-cylinder liner interface. Proc. IMechE. Part J: J. Engng. Trib. 219, 19-31 (2005)

[14] Baker, C.E., Theodossiades, S., Rahnejat, H., Fitzsimons B.: Influence of in-plane dynamics of thin compression rings on friction in internal combustion engines. Trans. ASME, J. of Eng. for Gas Turbines \& Power, 134, (2012), 092801

[15] Chong, W.W.F., Teodorescu, M., Vaughan N.D.: Cavitation induced starvation for piston-ring/liner tribological conjunction. Trib. Int., 44, 483-497 (2011)

[16] Elrod, H. G.: A Cavitation Algorithm. Trans. ASME, J. Lubn. Tech., 103, 350-354 (1981)

[17] Jakobsson, B., Floberg, L.: The Finite Journal Bearing Considering Vaporization. Trans. of Chalmers University of Tech., Gothenburg, Sweden, (1957) 
[18] Olsson, K. O.: Cavitation in dynamically loaded bearings. Trans. of Chalmers University of Technology, (1965)

[19] Haddad, S. D., Tian, K.T.: An analytical study of offset piston and crankshaft designs and the effect of oil film on piston slap excitation in a diesel engine. Mechanism and Machine Theory, 30, 271-284 (1995)

[20] Rahnejat, H.: Multi-body dynamics: vehicles, machines and mechanisms. Professional Engineering Publishing, Bury St Edmunds, UK: IMechE and Warrandale, PA, USA: SAE, joint publishers, (1998)

[21] Bin Chik, A., Fessler, H.: Radial pressure exerted by piston rings. J. Strain Anal Eng. Des. I, 2, 165-171 (1966)

[22] Felter, C. L.: Numerical simulation of piston ring lubrication. Trib. Int. 41, 914-919 (2008)

[23] White F. M., "Viscous Fluid Flow", McGraw-Hill, $2^{\text {nd }}$ Edition (1991)

[24] Senocak, I., Shyy, W., Interfacial dynamics-based modelling of turbulent cavitating Flows, Part-1: Model development and steady-state computations. Int. J. Numer. Meth. Fluids 44, 975-995 (2004)

[25] Singhal, A.K., Li, H.Y., Athavale M.M., Jiang Y.: Mathematical Basis and Validation of the Full Cavitation Model. ASME FEDSM'01, New Orleans, Louisiana, (2001)

[26] Kubota, A., Kato, H., Yamaguchi H.: A new modelling of cavitating flows: a numerical study of unsteady cavitation on a hydrofoil section. J. Fluid Mech. 240, 59-96 (1992)

[27] De la Cruz, M., Chong, W.W.F., Teodorescu, M., Theodossiades, S., Rahnejat, H.:

Transient mixed thermo-elastohydrodynamic lubrication in multi-speed transmissions. Trib.

Int. 49, 17-29 (2012)

[28] Dowson, D., and Higginson, G. R.: A Numerical Solution to the Elasto-Hydrodynamic

Problem. J. Mech. Eng. Sci. 1, 6-15 (1959)

[29] Roelands, C. J. A.: Correlational Aspects of the Viscosity-Temperature-Pressure Relationship of Lubricating Oils. Ph.D thesis, Technical University Delft, Delft, The Netherlands (1966)

[30] Houpert, L.: New results of traction force calculations in elasthydrodynamic contacts. $J$. Trib. - T. ASME 107, 241-248 (1985)

[31] Lee, P.M., Stark, M.S., Wilkinson, J.J., Priest, M., Lindsay Smith, J.R., Taylor, R.I., Chung, S.: The degradation of lubricants in gasoline engines: Development of a test procedure to evaluate engine oil degradation and its consequences for rheology. Trib. Inter. Eng. Series 48, 593-602 (2005)

[32] Olver, AV., Spikes, HA.: Prediction of traction in elastohydrodynamic lubrication. Proc IMechE, Part J: J. Eng. Trib. 212, 321-32 (1998)

[33] Eyring, H.: Viscosity, plasticity and diffusion as examples of reaction rates. $J$ Chem Phys. 4, 283-291 (1936)

[34] Greenwood, J.A., Tripp, J.H.: The contact of two nominally flat rough surfaces. Proc IMechE 185, 625-634 (1970-1971)

[35] Manninen, M., Taivassalo, V., Kallio, S.: On the mixture model for multiphase flow. VTT Publications 288 Technical Research Centre of Finland (1996)

[36] Sawicki, J. T., Yu, B.: Analytical Solution of Piston Ring Lubrication Using Mass Conserving Cavitation Algorithm. Tribology Transactions 43, 587-594 (2000)

[37] Snyder, D. O., Koutsavdis, E. K., Anttonen, J. S. R.: Transonic store separation using unstructured CFD with dynamic meshing". Technical Report AIAA-2003-3913, 33th AIAA Fluid Dynamics Conference and Exhibition, American Institute of Aeronautics and Astronautics (2003) 
[38] Furuhama S. and Sasaki S.: New device for the measurement of piston frictional forces in small engines. Society of Automotive Engineers, Pap. No. 831284 (1983)

[39] Gore, M., Theaker, M., Howell-Smith, S., Rahnejat, H., King, P.D.: Direct measurement of piston friction of internal combustion engines using the floating liner principle. Proc. Instn. Mech. Engrs., Part D: J. Auto. Engng., in review process

[40] Ghosh, MK., Gupta K.: Thermal effect in hydrodynamic lubrication of line contactspiezoviscous effect neglected. Int. J. Mech. Sci. 40, 603-616 (1998)

[41] Andersson, B.S., Company's pespective in vehicle tribology. Leeds-Lion sympc. on Tribology, 503-506 (1991)

[42] Chong, WWF., Teodorescu, M., Rahnejat, H.: Mixed thermo-elastohydrodynamic camtappet power loss in low-speed emission cycles. Int. J. Engine Res. (2012) doi: 10.1177/1468087412461631

[43] Rahnejat, H., Balakrishnan, S., King, P.D., Howell-Smith, S.: In-cylinder friction reduction using a surface finish optimization technique", Proc. IMechE, Part D: J. Automobile Eng. 220, 1309-1318 (2006)

[44] Ryk, G., Etsion, I.: Testing piston rings with partial laser surface texturing for friction reduction. Wear 261, 792-796 (2006)

\section{Nomenclature}

$\begin{array}{ll}A & \text { apparent contact area } \\ A_{a} & \text { asperity contact area } \\ b & \text { ring axial face-width } \\ C_{p} & \text { lubricant specific heat } \\ d & \text { ring thickness } \\ E_{1} & \text { Young's modulus of elasticity of the ring } \\ E_{2} & \text { Young's modulus of elasticity of the liner } \\ E^{\prime} & \text { equivalent (reduced) modulus of elasticity } \\ f_{b} & \text { boundary friction } \\ f_{t} & \text { total friction } \\ f_{v} & \text { viscous friction } \\ F_{T} & \text { ring tension force } \\ F_{G} & \text { combustion gas force }\end{array}$




\begin{tabular}{|c|c|}
\hline$F_{2}, F_{5 / 2}$ & statistical functions \\
\hline$g$ & ring end gap \\
\hline$g_{s}$ & switch function \\
\hline$H$ & enthalpy \\
\hline$h$ & elastic film shape \\
\hline$h_{m}$ & minimum film thickness \\
\hline$h_{s}$ & ring axial profile \\
\hline$h_{t}$ & heat transfer coefficient of boundary layer \\
\hline$I$ & ring cross-sectional second area moment of inertia \\
\hline$k$ & lubricant thermal conductivity \\
\hline$k_{s 1}$ & thermal conductivity of the bore/liner \\
\hline$k_{\text {s2 }}$ & thermal conductivity of the ring \\
\hline$l$ & connecting rod length \\
\hline$L$ & ring peripheral length \\
\hline$p_{a t m}$ & atmospheric pressure \\
\hline$p_{c}$ & cavitation/lubricant vaporisation pressure \\
\hline$p_{h}$ & hydrodynamic pressure \\
\hline$p_{g b}$ & gas pressure acting behind the ring \\
\hline$\dot{Q}_{1}$ & conductive heat flow rate through the liner \\
\hline$\dot{Q}_{2}$ & conductive heat flow rate through the ring \\
\hline$\dot{Q}_{c v}$ & convective heat flow rate \\
\hline$r$ & crank-pin radius \\
\hline$r_{0}$ & nominal bore radius \\
\hline
\end{tabular}


Tribology Letters, June 2013, DOI: 10.1007/s11249-013-0163-5

(Accepted Version)

$\begin{array}{ll}R_{l} & \text { conductive thermal resistance for the lubricant layer } \\ R_{v} & \text { convective thermal resistance of the boundary layer (between film and } \\ \text { surface) } & \\ \text { Re } & \text { Reynolds number } \\ t & \text { time } \\ U & \text { ring sliding velocity } \\ U_{1}, U_{2} & \text { surface velocities of contacting bodies } \\ \vec{V} & \text { velocity vector } \\ W & \text { contact load } \\ W_{a} & \text { load share of asperities } \\ W_{h} & \text { load carried by the lubricant film } \\ X_{c} & \text { oil film rupture point } \\ Z & \text { pressure-viscosity index }\end{array}$

\section{Greek symbols}

$\alpha_{0} \quad$ pressure/temperature-viscosity coefficient

$\beta \quad$ lubricant bulk modulus

$\varphi \quad$ crank angle

$\zeta \quad$ number of asperity peaks per unit contact area

$\eta \quad$ lubricant dynamic viscosity

$\eta_{0} \quad$ lubricant dynamic viscosity at atmospheric pressure

$\kappa \quad$ average asperity tip radius

$\lambda \quad$ Stribeck's oil film parameter

$\mu \quad$ pressure coefficient for boundary shear strength of asperities

$v_{1} \quad$ Poisson's ratio of the ring material 
Tribology Letters, June 2013, DOI: 10.1007/s11249-013-0163-5

\section{(Accepted Version)}

$v_{2}$

$\rho$

$\rho_{0}$

$\sigma_{r}$

$\sigma_{l}$

$\tau$

$\tau_{0}$

$\Gamma$

$\theta$

$\theta_{e}$
Poisson's ratio of the liner material

lubricant density

lubricant density at atmospheric pressure

liner surface roughness

ring surface roughness

shear stress

Eyring shear stress

diffusion coefficient

temperature

average (effective) lubricant temperature 